\section{Usos y Abusos de la Justicia Transicional en Colombia*}

\author{
Rodrigo Uprimny ${ }^{* *}$ y María Paula Saffon ${ }^{* * *}$
}

Este comentario, junto a los

documentos que analiza,

está disponible en

www.anuariocdh.uchile.cl

Durante muchos siglos, las transiciones de la guerra a la paz o del autoritarismo a la democracia fueron moldeadas casi por completo por la política. La necesidad de poner fin a la violencia determinaba cuáles eran las soluciones jurídicas que se adoptaban para lograr una transición. Así, el derecho no era visto como un límite real a la política de la transición, sino más bien como un instrumento para cumplir sus metas.

Esta situación ha cambiado en las últimas décadas. El auge de la conciencia humanitaria y la reciente evolución de los estándares internacionales y nacionales de derechos humanos ${ }^{1}$ han impuesto la necesidad de proteger los derechos de las víctimas de atrocidades cometidas en el régimen anterior a la transición. Esto explica que el uso del lenguaje de la justicia transicional se haya vuelto ineludible en contextos transicionales. De hecho, como el propio término lo indica, la justicia transicional busca dotar a las transiciones de justicia, es decir, enmarcar la política de las transiciones en ciertos estándares jurídicos -en particular aquéllos que se refieren a los derechos de las víctimas a la verdad, la justicia y la reparación ${ }^{2}$.

A pesar de lo anterior, todavía permanece abierta la pregunta de si los estándares jurídicos de la justicia transicional funcionan realmente como límites normativos efectivos a las opciones políticas que están disponibles para llevar a cabo una transición. Esto es así porque el uso de

* Este artículo es una traducción y actualización del siguiente texto de los autores: María Paula Saffon, Rodrigo Uprimny. "Uses and abuses of transitional justice in Colombia", presentado en el Seminario Internacional Paz y Responsabilidad en Transiciones de Conflictos Armados (Universidad del Rosario, junio 15 y 16 de 2007), que será publicado en Bergsmo, M. y Kalmanovitz, P (eds.). 2007. Law in Peace Negotiations, FICJC Publication Series 2 (2007), International Peace Research Institute in Oslo (PRIO).

** Director del Centro de Estudios de Derecho, Justicia y Sociedad, DeJuSticia, y profesor asociado de la Facultad de Derecho de la Universidad Nacional de Colombia.

*** Investigadora del Centro de Estudios de Derecho, Justicia y Sociedad, DejuSticia, y profesora de la Facultad de Derecho de la Universidad de los Andes y de la Universidad Nacional de Colombia.

1 Ver, entre otros, Joinet, L. (1997). ONU, Comisión de Derechos Humanos, $49^{\text {vo }}$ periodo de sesiones. Informe final revisado acerca de la cuestión de la impunidad de los autores de violaciones de los derechos humanos (derechos civiles y políticos) preparado por el Sr. L. Joinet de conformidad con la resolución 1996/119 de la Subcomisión. Doc. E/CN.4/ Sub.2/1997/20/Rev. 1; Orentlicher, D. (2004). ONU, Comisión de Derechos Humanos, 60vo periodo de sesiones. Estudio independiente, con inclusión de recomendaciones, sobre las mejores prácticas para ayudar a los Estados a reforzar su capacidad nacional con miras a combatir todos los aspectos de la impunidad. Doc. E/CN.4/ 2004/88. Para un análisis sistemático de estos estándares, ver Botero, C. y Restrepo, E. 2006. "Estándares internacionales y procesos de transición en Colombia", en Uprimny, R., Botero, C., Restrepo, E. y Saffon, MP. 2006. ¿Justicia transicional sin transición? Verdad, justicia y reparación para Colombia. Bogotá: DeJuSticia.

2 Esto no significa que la justicia transicional aspire a lograr que el derecho conquiste o impere por completo sobre la política de la transición, pues se trata de un tipo especial de justicia determinado y limitado por las dinámicas políticas de los tiempos de transición. En ese sentido, aunque la definición de justicia transicional dista mucho aún de ser aceptada unánimemente y es en cambio objeto de debates intensos, la idea de que la justicia transicional consiste en una serie de mecanismos o procesos dirigidos a lograr un equilibrio entre el imperativo jurídico de justicia par las víctimas y la necesidad política de paz es ampliamente aceptada. 
un discurso determinado -como el de la justicia transicional- no implica necesariamente una transformación en la práctica; dicho uso puede consistir simplemente en un giro retórico con efectos simbólicos o legitimadores. Por eso, es importante analizar cuidadosamente si el lenguaje de la justicia transicional puede servir intereses distintos, y en particular, si puede ser utilizado no sólo para promover efectos transformadores, sino también para perpetuar el statu quo ${ }^{3}$. Y por eso también es importante establecer si el reciente uso recurrente de la justicia transicional implica el imperio de la ley por sobre la política al menos en ciertos asuntos, o si la política continúa aún moldeando por completo las fórmulas jurídicas en contextos de transición.

El propósito de este artículo es abordar estos problemas. Desde una perspectiva conceptual, el artículo busca reflexionar sobre la relación existente entre derecho y política, y en particular entre los estándares jurídicos que consagran los derechos de las víctimas, por un lado, y las dinámicas políticas que subyacen y a la vez determinan los resultados de una transición -en especial de una transición negociada-, por otro. Esta reflexión será aplicada al caso colombiano, pues la misma resulta muy útil para comprenderlo adecuadamente. En particular, el artículo se enfocará en el rol que los mecanismos de justicia transicional -y especialmente el reconocimiento de los derechos de las víctimas- juegan en las actuales negociaciones de paz entre el gobierno colombiano y los grupos paramilitares. Desde ese punto de partida, el artículo intentará arribar a algunas conclusiones, que tal vez puedan ser extendidas al análisis de otras situaciones.

El artículo está dividido en tres secciones principales. La primera sección contiene una breve caracterización del caso colombiano, que hace un énfasis especial en las complejidades derivadas del uso del lenguaje y los mecanismos de la justicia transicional en contextos en los cuales una transición total o completa no está teniendo lugar. La segunda sección del artículo analiza el rol de la justicia transicional -y en particular del reconocimiento de los derechos de las víctimas- en transiciones negociadas, a través de dos variables: (i) los diferentes posibles usos -manipuladores o democráticos- del discurso de la justicia transicional, en función de los diferentes intereses que puede servir, y (ii) la relación que existe entre los valores de justicia y paz. Tras una reflexión conceptual sobre cada variable, las mismas son aplicadas al caso colombiano. La tercera y última sección del artículo esboza algunas consideraciones finales sobre la importancia de llevar a cabo un uso cauteloso del discurso de la justicia transicional en el contexto colombiano, que pueden ser extensibles al uso de otras situaciones.

\section{El caso colombiano: ijusticia transicional sin transición? ${ }^{4}$}

Las complejidades de la relación entre los estándares jurídicos de la justicia transicional y la política de las transiciones -y en particular de las transiciones negociadas- se agudizan en el caso colombiano. Esto es así no sólo por las características particulares del conflicto armado colombiano y del contexto en el que se desarrolla, sino también porque en él se presenta una situación muy paradójica: a pesar de que el país está en medio de un conflicto armado aún en curso, el lenguaje de la justicia transicional es utilizado recurrentemente.

\footnotetext{
3 Para las categorías de efectos transformadores o emancipatorios, por un lado, y de efectos perpetuadores o legitimadores, por otro, ver, entre muchos otros, Santos de Sousa, B. 1998. La globalización del derecho. Bogotá: Universidad Nacional de Colombia e ILSA; Kennedy, D. 1999. Libertad y restricción en la decisión judicial. El debate con la Teoría Crítica del Derecho (CLS). Bogotá: Siglo del Hombre Editores (Diego Eduardo López ed.).

4 Éste es el título de un libro del cual son coautores los autores de este artículo: Uprimny, Botero, Restrepo y Saffon, Ob. Cit.
} 


\section{A. Complejidad del conflicto colombiano}

El conflicto armado interno colombiano es muy complejo ${ }^{5}$, no sólo por sus características específicas, sino también por los elementos propios del contexto en el cual se desarrolla.

Hay varias características del propio conflicto colombiano que lo hacen complejo. En primer lugar, se trata de uno de los conflictos armados más largos del mundo ${ }^{6}$. Los análisis más prudentes hablan de 1964 como el origen contemporáneo del conflicto colombiano, pues éste fue el año en el que las Fuerzas Armadas Revolucionarias de Colombia (FARC) se alzaron en armas ${ }^{7}$. Sin embargo, muchos otros analistas apuntan al periodo de La Violencia de los años cuarenta como el origen del conflicto tal y como lo conocemos hoy en día ${ }^{8}$. Sea como fuere, el conflicto colombiano ha durado por lo menos cuarenta años, y esa situación sin duda dificulta la tarea de lograr una paz negociada que sea duradera.

En segundo lugar, el conflicto colombiano no se desarrolla entre dos facciones -como sucede usualmente-, sino que incluye varios actores: el Estado, los grupos guerrilleros y los grupos paramilitares. En el país han existido varios grupos guerrilleros subversivos que han confrontado la autoridad del Estado en el territorio nacional ${ }^{9}$. Actualmente, sólo dos de esos grupos permanecen aún activos, y uno de ellos, el Ejército de Liberación Nacional (ELN) se encuentra en las primeras etapas de negociaciones de paz con el gobierno, cuyos resultados aún son inciertos. No obstante, las FARC, el otro grupo guerrillero, no ha demostrado un interés serio de adelantar negociaciones de paz con el gobierno, y en los últimos años ha continuado e incluso incrementado la comisión de atrocidades contra la sociedad civil, que incluyen especialmente secuestros y asesinatos.

Pero los grupos guerrilleros y el ejército no son los únicos actores del conflicto colombiano. En los años ochenta fueron creados grupos paramilitares de derecha con la justificación de la necesidad de combatir a la guerrilla de manera más intensa. Estos grupos se expandieron rápidamente en términos tanto de número como de poder ${ }^{10}$. Para lograrlo, mantuvieron estrechos vínculos con las élites económicas, y establecieron fuertes relaciones de tolerancia, colaboración y complicidad con agentes estatales, que no sólo incluyen a los miembros de la fuerza pública11, sino

5 Para el estudio de las complejidades del conflicto colombiano y de las dificultades de su caracterización, ver IEPRI (ed.). 2006. Nuestra guerra sin nombre. Transformaciones del conflicto en Colombia. Bogotá: Norma.

6 Junto con el conflicto palestino-israelí y el conflicto entre la India y Paquistán. Al respecto, ver Comisión Nacional de Reparación y Reconciliación (CNRR). 2006. Hoja de Ruta, disponible en: www.cnrr.org.co/hoja_de_ruta.htm

7 La CNRR ha usado esta fecha para identificar preliminarmente el universo de las víctimas del conflicto colombiano, lo cual ha generado mucha controversia. Ver CNRR. 2006. Fundamentos Filosóficos y Operativos. Definiciones estratégicas de la Comisión Nacional de Reparación y Reconciliación, disponible en: www.cnrr.org.co/cd/pdf/Definiciones_estratergicas. pdf.

8 Gonzalo Sánchez ha argumentado que, a pesar de sus diferentes ciclos y lógicas, el conflicto colombiano es uno solo. Ver Sánchez, G. y Peñaranda, R. 1991. Pasado y presente de la violencia en Colombia. Bogotá: IEPRI-CEREC.

9 Además de las FARC y el ELN, que aún existen y confrontan al Estado, en Colombia han existido otros grupos guerrilleros que se han desmovilizado, como el Movimiento 19 de Abril (M-19), el Ejército de Liberación Popular (ELP) y el grupo guerrillero indígena Quintín Lame, entre otros.

10 Sobre su expansión numérica, ver Romero, M. 2003. Paramilitares y autodefensas. 1982-2003. Bogotá: IEPRI-Planeta. Sobre su expansión política y económica, ver Duncan, G. 2006. Los señores de la guerra: de paramilitares, mafiosos y autodefensas en Colombia Bogotá: Planeta. Ver también Saffon, MP. 2006. Poder paramilitar y debilidad institucional. El paramilitarismo en Colombia: un caso complejo de incumplimiento de normas. Bogotá: Universidad de los Andes, tesis de maestría.

11 Al respecto, ver los cinco casos decididos por la Corte Interamericana de Derechos Humanos contra el Estado colombiano en relación con masacres cometidas por grupos paramilitares con la colaboración o gracias a la omisión de agentes de la fuerza pública. Corte Interamericana de Derechos Humanos, Caso de la masacre de 19 Comerciantes vs. Colombia, sentencia de julio 5, 2004, serie C No 109; Caso de la masacre de Mapiripán vs. Colombia, sentencia de septiembre 15, 2005, serie C No 134; Caso de la masacre de Pueblo Bello, sentencia de enero 31, 2006, serie C No 140; Caso de las masacres de Ituango vs. Colombia, sentencia de julio 1, 2006, serie C No 149; Caso de la masacre de La Rochela vs. Colombia, sentencia de mayo 11, 2007, serie C N ${ }^{\circ} 163$. 
también a agentes de la inteligencia, a políticos locales y a congresistas ${ }^{12}$. Los paramilitares han cometido crímenes horribles contra la población civil, que incluyen particularmente masacres, desapariciones y desplazamientos forzados. En el año 2002, casi todos los grupos paramilitares que conforman la confederación de las Autodefensas Unidas de Colombia (AUC) negociaron un acuerdo de paz con el gobierno, que ha producido la desmovilización de más de 30.000 paramilitares, y el inicio de juicios penales contra casi 3.000 de ellos ${ }^{13}$. Sin embargo, por varias razones, la naturaleza de estos grupos hace más difícil encontrar fórmulas para asegurar que las negociaciones de paz garantizarán efectivamente el desmonte de sus estructuras de poder y la no repetición de las atrocidades.

De un lado, se trata de actores pro sistémicos ${ }^{14}$, que nunca combatieron al Estado sino que, por el contrario, apoyaron su lucha contra los grupos guerrilleros a través de medios ilegales. Por eso, durante muchos años los paramilitares no fueron perseguidos por el Estado ${ }^{15}$; por el contrario, éste se benefició de su actividad antisubversiva. De otro, los grupos paramilitares no están organizados jerárquicamente ni tienen un mando único o centralizado, sino que más bien funcionan como células semiautónomas de estructura nodal ${ }^{16}$. Finalmente, gracias a sus lazos con agentes del Estado, élites terratenientes regionales y el narcotráfico, los grupos paramilitares construyeron unas estructuras de poder político y económico mucho más fuertes e importantes que su poder militar ${ }^{17}$. Estas características de los grupos paramilitares sugieren que la paz y la garantía de no repetición de las atrocidades no pueden lograrse simplemente a través de un proceso de desmovilización. En efecto, por sí solo, un proceso de esa naturaleza puede permitir que esas estructuras de poder permanezcan intactas, e incluso que salgan fortalecidas en virtud de un proceso de legalización.

Además de los actores previamente mencionados, el rol central que ha jugado el narcotráfico en el conflicto armado colombiano no puede ignorarse ${ }^{18}$. Los narcotraficantes sostienen complejas relaciones con los grupos armados, que van desde la financiación de sus actividades hasta una participación más directa en ellas -que en algunos casos incluso ha implicado que los narcotraficantes se conviertan en líderes visibles de los grupos armados-. Esta intervención del narcotráfico en el conflicto armado ha contribuido de manera significativa a su perpetuación, en la medida en que funciona como una fuente casi ilimitada de financiación.

En tercer lugar, la propia naturaleza del conflicto armado constituye un elemento de complejidad del conflicto colombiano. En efecto, en razón de su carácter prolongado y de la multiplicidad y

12 Ver Duncan, Ob. Cit.; Saffon, Ob. Cit.

13 El marco jurídico de estos acontecimientos está compuesto por las leyes 782 de 2002 y 975 de 2005, así como por sus decretos reglamentarios.

14 En oposición a los actores antisistémicos como los grupos guerrilleros. Para un desarrollo de esta diferencia, ver Múnera, L. 2006. "Proceso de paz con actores armados ilegales y parasistémicos (los paramilitares y las políticas de reconciliación en Colombia)", Revista Pensamiento Jurídico № 17.

15 Para un análisis del marco jurídico con base en el cual se crearon muchos grupos paramilitares, ver Corte Interamericana de Derechos Humanos, Caso de la masacre de 19 Comerciantes vs. Colombia, sentencia de julio 5, 2004, serie C N 109 ; Caso de la masacre de Mapiripán vs. Colombia, sentencia de septiembre 15, 2005, serie C № 134; Caso de la masacre de Pueblo Bello, sentencia de enero 31, 2006, serie C No 140; Caso de las masacres de Ituango vs. Colombia, sentencia de julio 1, 2006, serie C No 149; Caso de la masacre de La Rochela vs. Colombia, sentencia de mayo 11, 2007, serie $C \mathrm{~N}^{\mathrm{o}} 163$.

16 Ver, al respecto, Alonso, M., Giraldo, J., y Alonso, D. 2005. "Medellín: El complejo camino de la competencia armada", en Diálogo Mayor. Memoria colectiva, reparación, justicia y democracia: el conflicto colombiano y la paz a la luz de experiencias internacionales. Bogotá: Universidad del Rosario.

17 Duncan, Ob. Cit.

18 Ver López, A. 2006. "Narcotráfico, ilegalidad y conflicto en Colombia" en IEPRI (ed.), Ob. Cit. 
heterogeneidad de sus actores, existe mucha discusión sobre la manera como el conflicto debería definirse: algunos hablan de guerra civil; otros hablan de amenaza terrorista; también podría describirse como una guerra contra la sociedad. Por eso, el título del reciente libro del IEPRI, Nuestra guerra sin nombre ${ }^{19}$, resulta muy sugestivo para pensar el conflicto colombiano.

En cuarto lugar, la magnitud y dramática situación de las víctimas en Colombia añaden complejidad al conflicto. Hay aproximadamente tres millones de víctimas de desplazamiento forzado interno ${ }^{20}$, que con frecuencia han sido también víctimas de otros crímenes y amenazas, y que han perdido sus tierras y demás pertenencias. La situación de la población desplazada constituye una verdadera tragedia humanitaria, ya que las víctimas del conflicto colombiano tienden a ser uno de los sectores más vulnerables y marginados de la sociedad, no sólo por los sufrimientos a los que se vieron sometidas, sino también por la situación socioeconómica a la que tales sufrimientos las han empujado. Fuera de la población desplazada, existen también miles de víctimas de otros crímenes atroces, que incluyen homicidios, desapariciones forzadas, violencia sexual, intolerancia social, secuestros extorsivos, masacres, detenciones arbitrarias, entre otros ${ }^{21}$. En general, las víctimas colombianas pertenecían a los sectores menos favorecidos de la sociedad incluso con anterioridad a la comisión de las atrocidades ${ }^{22}$.

Además de las características antes mencionadas inherentes al conflicto colombiano, hay algunos elementos propios del contexto en el cual se desarrolla que lo hacen aún más complejo. El primer elemento tiene que ver con la profunda influencia que la comunidad internacional en general, y Estados Unidos en particular, ejercen sobre la política colombiana. Esta influencia ha conducido a la internacionalización del conflicto colombiano, que se ha hecho cada vez más evidente. La preocupación de la comunidad internacional por la crisis humanitaria que vive Colombia, y en especial el interés de Estados Unidos en la política antidrogas, han moldeado en buena medida tanto la dinámica del conflicto, como el tratamiento jurídico de los actores armados desmovilizados.

De hecho, dado que los grupos armados colombianos están seriamente implicados en el narcotráfico, Estados Unidos ha incrementado su participación en el conflicto colombiano en los últimos diez años, especialmente a través del Ilamado "Plan Colombia". Más aún, los líderes

19 IEPRI (ed.), Ob. Cit.

20 Las fuentes oficiales indican que la población desplazada asciende a un poco más de dos millones de personas. Ver Acción Social, Estadísticas de la población desplazada, disponible en: www.accionsocial.gov.co/contenido/contenido. aspx?catID=383\&conID=556). Sin embargo, ésta es una cifra que sólo incluye a los desplazados oficialmente registrados como tales en el Registro Único de Población Desplazada del gobierno y que, por tanto, excluye a los desplazados que no han podido registrarse por diversas razones. Dado el serio problema de subregistro de la población desplazada, otras fuentes, como la Oficina del Alto Comisionado de las Naciones Unidas para los Refugiados (ACNUR), hablan de alrededor de tres millones de personas. Ver ACNUR, 2006. Global Trends Refugees, Asylum-seekers, Returnees, Internally Displaced and Stateless Persons, junio, 2007, disponible en: www.unhcr.org/statistics.html.

21 Para algunos cálculos preliminares de la cifra total de víctimas en Colombia y del costo de su reparación, ver González, C. "Prólogo". 2007, en Las cifras del conflicto. Bogotá: INDEPAZ; Richards, M. 2007. Quantification of the financial resources required to repair victims of the Colombian conflict in accordance with the Justice and Peace Law. Bogotá: CERAC.

22 Esto es así, tal vez con excepción de las víctimas de secuestro extorsivo. El perfil socioeconómico de las víctimas hace que el caso colombiano se parezca al de Guatemala -donde la mayoría de las víctimas eran Mayas-y al de Perú -donde la mayoría de las víctimas provenían del sector rural-, y se distinga de aquéllos de Argentina y Chile -donde las víctimas pertenecían sobre todo a la clase media-. En artículos anteriores, los autores hemos defendido la idea de que el perfil socioeconómico de las víctimas es muy importante para determinar la naturaleza que deberían tener las reparaciones, y en especial para establecer si éstas deberían tener un potencial transformador en lugar de tener un carácter meramente restitutivo. Ver Uprimny, R. y Saffon, MP. 2007. “Plan Nacional de Desarrollo y reparaciones. Propuesta de un programa nacional masivo de reparaciones administrativas para las víctimas de crímenes atroces en el marco del conflicto armado". Bogotá: CODHES. En prensa. 
paramilitares desmovilizados han sido pedidos en extradición por el gobierno estadounidense. Aunque en principio el gobierno colombiano ha expresado que no las hará efectivas, tales solicitudes de extradición han jugado un rol central en las negociaciones de paz con los paramilitares. En efecto, mientras que los paramilitares las ven como un incentivo para lograr un acuerdo de desmovilización, el gobierno las ha utilizado como una amenaza en caso de que los paramilitares no cumplan sus compromisos ${ }^{23}$.

El segundo elemento de complejidad del contexto en el que se desarrolla el conflicto colombiano consiste en la naturaleza ambigua del régimen político. A pesar de la persistencia del conflicto armado y de la gravedad de los abusos a los derechos humanos que se producen en su seno, las instituciones colombianas han logrado mantener importantes rasgos democráticos. Por ejemplo, regularmente se realizan elecciones -aunque cada vez más son interferidas por los grupos armados-, y el sistema judicial mantiene un significativo nivel de independencia y logra controlar algunos abusos de poder ${ }^{24}$. Por ende, es posible denominar la situación institucional colombiana como una peligrosa democracia en peligro, que es muy riesgosa para los ciudadanos, pero que a la vez se encuentra seriamente amenazada por los actores armados.

El tercer y último elemento del contexto que añade complejidad al conflicto tiene que ver con la profunda polarización de la sociedad colombiana. Esta polarización trae como resultado una tendencia a criticar más severamente o a sólo criticar la violencia producida por uno de los lados del conflicto -dependiendo del lado del espectro político en el que se encuentra el crítico-. Como consecuencia de esta tendencia, no hay un rechazo unánime a las graves violaciones de derechos humanos cometidas por todos los actores del conflicto, rechazo que resulta esencial para lograr una paz duradera.

Un ejemplo ilustra esta situación. Algunas decisiones judiciales, los medios de comunicación y las confesiones de los victimarios han revelado la crueldad de los métodos usados por los paramilitares para desaparecer forzosamente, torturar, asesinar y ocultar los restos de sus víctimas, así como la complicidad de muchos miembros del ejército, políticos locales, congresistas y colaboradores cercanos del Presidente Uribe con el paramilitarismo ${ }^{25}$. A pesar de ello, como lo muestra una encuesta reciente hecha por la Revista Semana, muchas personas no rechazan completamente las atrocidades cometidas por los paramilitares, ni los estrechos vínculos entre éstos y agentes del Estado. Según la encuesta, el conocimiento de los crueles mecanismos utilizados por los paramilitares para cometer atrocidades contra civiles no afectó la percepción positiva que la gente tenía de ellos en 38\% de los casos, y aumentó dicha percepción positiva en $9 \%$ de los casos. Más aún, el $73 \%$ de la población cree que el gobierno debería hacer un mayor esfuerzo por combatir a los grupos guerrilleros que a los grupos paramilitares, y el $47 \%$ de la población cree que los grupos guerrilleros son más responsables de la violencia del país que el resto de los actores armados ${ }^{26}$.

23 Al respecto, ver el interesante análisis contenido en la introducción de: Bergsmo, M. y Kalmanovitz, P (eds.). 2007. Law in Peace Negotiations, FICJC Publication Series 2 (2007), International Peace Research Institute in Oslo (PRIO).

24 Esto es así con excepción de los jueces que operan en zonas de conflicto armado, en las cuales los actores armados intervienen en su actividad, o bien decidiendo directamente los casos de su competencia, o bien amenazándolos. Para una breve referencia a este fenómeno, ver Uprimny, R. 2006. "Entre el protagonismo, la precariedad y las amenazas: las paradojas de la judicatura", en Leal, F. (ed.), En la encrucijada, Colombia siglo XXI. Bogotá: Norma.

25 Ver, entre muchas otras referencias de prensa "Juicio histórico a paramilitares", El Tiempo, abril 23 de 2007 ; "Parapolíticos" y "El ventilador de Mancuso", Revista Semana, mayo 19 de 2007.

26 Ver "La gran encuesta de la parapolítica", Revista Semana, mayo 5 de 2007. 


\section{B. El uso de la justicia transicional en medio del conflicto armado}

Como lo mostramos en la sección anterior, a pesar de la masiva desmovilización de paramilitares que ha tenido lugar recientemente, el conflicto interno armado en Colombia aún dista mucho de llegar a su fin. De un lado, el conflicto con los grupos guerrilleros, y en particular con las FARC, ha continuado e incluso se ha intensificado en los últimos años. Más aún, la existencia de un acuerdo de paz con las FARC no parece una posibilidad real al menos en el corto plazo. De otro, existen muchas dudas sobre la posibilidad de que la desmovilización de los paramilitares conduzca al desmonte de sus estructuras de poder, lo cual pone en riesgo la garantía de no repetición de las atrocidades y la sostenibilidad de la paz.

En ese contexto, no parece adecuado o preciso hablar de una transición de la guerra a la paz en Colombia. Una transición total o completa no está teniendo lugar, dado que las recientes negociaciones no han incluido a todos los actores armados. Más aún, es posible decir que tampoco está teniendo lugar una transición fragmentaria o parcial en relación con los grupos paramilitares porque, incluso si sus miembros han entregado sus armas, al parecer sus organizaciones económicas y políticas permanecen intactas.

No obstante, desde hace algunos años, todo el mundo habla sobre justicia transicional en Colombia. De hecho, la mayoría de los actores involucrados en la discusión política sobre cómo enfrentar las atrocidades cometidas por los paramilitares promueven explícitamente el uso del lenguaje y los mecanismos de la justicia transicional, o por lo menos implícitamente usan la lógica y las categorías de la justicia transicional para analizar la situación colombiana. Este uso generalizado de la justicia transicional no sólo es paradójico por la obvia razón de que tiene lugar en medio de un conflicto armado que no muestra claras señales de una transición. Lo que parece más paradójico de esta situación es que, mientras que al comienzo de las discusiones ninguno de los actores usaba o pretendía usar el discurso de la justicia transicional, por razones muy distintas, todos terminaron adoptándolo.

Ése es, sin lugar a dudas, el caso del gobierno y de los propios grupos paramilitares, que en las primeras etapas del proceso rechazaban abiertamente la aplicación de la justicia penal a las atrocidades cometidas por los paramilitares, pero que pronto empezaron a utilizar el discurso de la justicia transicional y a admitir la necesidad de un grado mínimo de castigo que dicho discurso implica. De hecho, en los inicios de la discusión sobre el marco jurídico para la desmovilización del paramilitarismo, los líderes paramilitares dijeron enfáticamente que no pasarían ni un día en la cárcel ${ }^{27}$. Por su parte, el gobierno defendió la importancia de la paz y la reconciliación, invocando el paradigma de la justicia restaurativa -defendido, entre muchos otros, por Desmond Tutu en la transición sudafricana- como el marco conceptual más adecuado para las negociaciones con los paramilitares. Como resultado, el primer proyecto de ley, titulado Ley de Alternatividad Penal, propuesto por el gobierno al Congreso en el año 2003, implicaba la concesión de amnistías a todos los actores armados que aceptaran desmovilizarse, y se fundaba en la idea restaurativa de que el castigo penal no contribuye e incluso puede convertirse en un obstáculo para lograr la reconciliación ${ }^{28}$.

Sin embargo, el proyecto de ley fue rápidamente retirado del Congreso, como consecuencia de las duras críticas que recibió de parte de diferentes sectores, y particularmente de las organizaciones

\footnotetext{
27 Declaración de Salvatore Mancuso, líder y vocero paramilitar del momento, en una audiencia en el Congreso. Ver "Vinieron, hablaron y se fueron. Armando Neira relata en exclusiva para SEMANA.COM los detalles de la polémica visita de los paramilitares al Congreso", Semana.com, julio 29 de 2005.

28 Ver Gaceta del Congreso № 436 de 2003.
} 
locales de derechos humanos, de las organizaciones de víctimas y de algunos grupos políticos. Según estos sectores, el proyecto de ley era, en realidad, una ley de impunidad, ya que apuntaba a ser aplicada a todos los actores armados -incluidos aquéllos que han cometido infracciones del derecho internacional humanitario y graves violaciones de los derechos humanos-, y no condicionaba los beneficios que concedía a la efectiva satisfacción de los derechos de las víctimas. El gobierno reemplazó el proyecto de ley por otro que después se convirtió en la ley 975 de 2005, comúnmente conocida como la ley de Justicia y Paz.

Este nuevo proyecto de ley implicó un cambio importante en el discurso del gobierno, que pasó del rechazo absoluto del castigo penal y del silencio total sobre los derechos de las víctimas, a la admisión de la importancia de lograr un equilibrio entre las necesidades de paz y las exigencias de justicia. En el proyecto de ley, este cambio se tradujo en el reconocimiento de los derechos de las víctimas, en la imposición de un castigo criminal muy indulgente (de máximo ocho y mínimo cinco años, sin importar la cantidad y gravedad de los crímenes) para los actores desmovilizados que han cometido atrocidades, y en la exigencia de deberes mínimos en relación con la verdad y la reparación de las víctimas ${ }^{29}$.

Aunque esta nueva propuesta legal alteró las condiciones iniciales bajo las cuales los paramilitares decidieron desmovilizarse, éstos nunca retaron o rechazaron abiertamente el texto. Más aún, cuando la Corte Constitucional revisó la constitucionalidad de la ley, los líderes paramilitares defendieron su texto original y lo trataron como una promesa que no debería romperse ${ }^{30}$. De esa manera, el cambio de discurso también puede ser atribuido a los líderes paramilitares, quienes pasaron de sostener que no pasarían ni un solo día en la cárcel, a aceptar la posibilidad de un castigo penal reducido.

El cambio de discurso antes descrito no significa que el enfoque y los objetivos iniciales tanto del gobierno como de los paramilitares hayan cambiado más que semánticamente. Como muchas ONGs y una minoría de congresistas lo señalaron, el nuevo proyecto del ley propuesto por el gobierno y finalmente aprobado por el Congreso no contenía los mecanismos necesarios para asegurar que los derechos de las víctimas allí reconocidos serían protegidos adecuadamente ${ }^{31}$. De esa manera, la ley de Justicia y Paz fue criticada como una forma más sutil y disfrazada de impunidad y, por esa razón, su texto fue atacado en el Congreso y su constitucionalidad fue cuestionada ante la Corte Constitucional inmediatamente después de su promulgación.

La estrategia utilizada por las organizaciones de víctimas y de derechos humanos para atacar la ley de Justicia y Paz en el seno del Congreso y ante la Corte Constitucional también implicó un giro en su discurso. En efecto, estas organizaciones utilizaron de manera importante la lógica y las categorías de la justicia transicional para oponerse a la ley. Este uso de la justicia transicional implica una tensión con la idea, defendida por la mayoría de estas organizaciones, de que en Colombia no hay ni una transición ni un contexto transicional ${ }^{32}$. Además, este uso de la justicia

29 En relación con la verdad, la ley exigía que los desmovilizados confesaran los crímenes en los que habían participado, pero no establecía la pérdida de los beneficios penales en caso de confesiones falsas o incompletas. En relación con la reparación, la ley sólo exigía que los desmovilizados entregaran los bienes ilegalmente obtenidos que aún poseían, permitiéndoles así conservar la mayoría de sus bienes, a través de procesos de lavado de activos, de transferencia a testaferros, o de legalización de bienes ilegales. Este proyecto fue promovido, al interior del Congreso, por los Congresistas Mario Uribe, Claudia Blum, José Renán Trujillo, Luis Humberto Gómez, Ciro Ramírez, Germán Vargas, Roberto Camacho, Armando Benedetti, José Luis Arcila, Óscar Arboleda, Iván Díaz, Germán Varón.

30 En este sentido, ver Bergsmo y Kalmanovitz, Ob. Cit.

31 Para un análisis detallado de las debilidades de la ley para lograr una adecuada protección de los derechos de las víctimas, ver Uprimny, R. y Saffon, MP. 2006. "La ley de 'justicia y paz': ¿una garantía de justicia y paz y de no repetición de las atrocidades?", en Uprimny, R., Restrepo, E., Botero, C., Saffon, MP, Ob. Cit.

32 Al respecto, ver Cepeda, I. 2007. Conferencia para el panel "Fundamentos éticos y políticos para la reconstrucción del país", presentada en el seminario Reconstrucción de Colombia, organizado por Planeta Paz, DeJuSticia, CODHES, 
transicional contrasta con el enfoque maximalista y basado en derechos que estas organizaciones adoptaron en las primeras etapas de la discusión política sobre el marco jurídico, de conformidad con el cual los derechos de las víctimas deberían protegerse sin restricción. Y en particular sin importar la necesidad política de lograr la paz ${ }^{33}$.

Durante la discusión de los proyectos de ley tendientes a dotar de un marco jurídico al proceso de desmovilización, estas organizaciones pasaron a una posición menos radical, que admitía que un arreglo negociado podría implicar la existencia de una fórmula jurídica específica capaz de responder a la necesidad política de lograr la paz, pero que en todo caso insistiera en la importancia de proteger adecuadamente los derechos de las víctimas y de asegurar la garantía de no repetición. De ese modo, a pesar de negar la existencia de una transición en Colombia, las organizaciones de víctimas y de derechos humanos hicieron uso del principio central de la justicia transicional que -como lo hemos ya mencionado- consiste en la necesidad de lograr un equilibrio entre las exigencias de paz y justicia.

Por esa razón, estas organizaciones apoyaron el proyecto alternativo promovido por algunos congresistas, que también admitía la posibilidad de un castigo penal reducido, pero establecía que el mismo debía ser proporcional a los crímenes cometidos, y sólo debía ser concedido si cada beneficiario confesaba todos los crímenes en los cuales había participado e integraba integralmente a sus víctimas ${ }^{34}$. Una vez este proyecto de ley fue derrotado por la ley de Justicia y Paz, las organizaciones de víctimas y de derechos humanos también utilizaron la lógica y las categorías de la justicia transicional para cuestionar la constitucionalidad de esta última, alegando esencialmente que la misma violaba flagrantemente los derechos de las víctimas a la verdad, la justicia y la reparación, y que en consecuencia no buscaba ni lograba un equilibrio entre paz y justicia $^{35}$.

En el año 2006, la Corte Constitucional profirió la sentencia C-370 de 2006, la más importante de una serie de sentencias referentes a la constitucionalidad de diferentes disposiciones de la ley de Justicia y $\mathrm{Paz}^{36}$. En su sentencia, la Corte estableció explícitamente que la ley estaba fundada en el principio central de la justicia transicional de acuerdo con el cual es esencial lograr un equilibrio entre la necesidad política de paz y el imperativo jurídico de proteger los derechos de las víctimas. Por esa razón, la Corte decidió que la idea general de la ley, de conformidad con la

Fundación Manuel Cepeda Vargas y Unijus. Bogotá, agosto de 2007. Esta tensión permanece y, en nuestro concepto, se hace cada vez más inevitable. De hecho, aunque no es nada claro que una transición esté teniendo lugar en Colombia, el uso del discurso de la justicia transicional se ha hecho ineludible y, como lo discutiremos en la siguiente sección, parece ofrecer elementos importantes para la defensa de los derechos de las víctimas y para el empoderamiento de sus organizaciones.

33 Esta posición inicial se refleja en el proyecto de ley presentado por la Senadora Piedad Córdoba como otra alternativa al proyecto de ley de Justicia y Paz, titulado "(p)or la cual se dictan normas sobre Verdad, Justicia, Reparación, Prevención, Publicidad y Memoria para el sometimiento de los grupos paramilitares que adelanten diálogos con el gobierno", y Ricardo Español, "Por la paz y la reconciliación nacional (reparación y rehabilitación)".

34 El proyecto de ley alternativo fue promovido por los congresistas Rafael Pardo, Gina Parody, Rodrigo Rivera, Luis Fernando Velasco, Carlos Gaviria y Germán Navas, y su título era el siguiente: "(P)or la cual se dictan disposiciones para garantizar los derechos a la verdad, la justicia y la reparación de las víctimas de violaciones a los derechos humanos y de la sociedad colombiana en procesos de reconciliación con grupos armados al margen de la ley". Entre otros asuntos, este proyecto alternativo incluía la obligación de los victimarios de reparar a sus víctimas con bienes tanto legales como ilegales, y la obligación del Estado de reparar en caso de insuficiencia de bienes o de imposibilidad de individualizar al victimario.

35 La sentencia C-370 de 2006 de la Corte Constitucional contiene un resumen de los argumentos de las organizaciones que se oponían a la ley, y que presentaron la primera acción de inconstitucionalidad en su contra.

36 Además de la sentencia C-370 de 2006, la Corte Constitucional ha proferido las siguientes sentencias sobre la constitucionalidad de la ley de Justicia y Paz: sentencias C-127 de 2006, C-319 de 2006, C-455 de 2006, C-531 de 2006, C-575 de 2006, C-650 de 2006, C-670 de 2006, C-719 de 2006, C-080 de 2007. 
cual un castigo penal reducido podía justificarse con el fin de alcanzar la paz, era aceptable. No obstante, la Corte estableció que una reducción tal del castigo penal debía estar acompañada de mecanismos adecuados para lograr una protección suficiente e idónea de los derechos de las víctimas, en ausencia de la cual estos derechos se veían afectados desproporcionadamente y el principio de la justicia transicional se rompía. Según la Corte, esto era lo que sucedía con varias disposiciones de la ley de Justicia y Paz, que no contenían garantías suficientes para la satisfacción de los derechos de las víctimas, y que por lo tanto violaban los estándares internacionales y constitucionales en la materia ${ }^{37}$. En consecuencia, la Corte declaró la inconstitucionalidad de algunas de esas disposiciones ${ }^{38}$ y la constitucionalidad condicionada de otras ${ }^{39}$.

Como lo muestra la descripción precedente, los diferentes actores políticos que lucharon por definir el contenido del marco jurídico de las negociaciones con los paramilitares terminaron usando el lenguaje y las categorías de la justicia transicional. En particular, los discursos de todos esos actores coinciden en dos ideas básicas de la justicia transicional: (i) el principio de acuerdo con el cual es necesario hallar un equilibrio entre paz y justicia; (ii) el reconocimiento del carácter normativo y de la aplicabilidad de los derechos de las víctimas a la verdad, la justicia y la reparación. Sin embargo, esta coincidencia no fue el resultado de un acuerdo o consenso general entre los diferentes actores sobre la conveniencia de utilizar el lenguaje de la justicia transicional. Por el contrario, la coincidencia se dio a pesar de que, al comienzo de las discusiones, ninguno de esos actores estaba interesado en ni tenía el deseo de usar las categorías y el lenguaje de la justicia transicional.

¿Cómo puede explicarse una coincidencia tan involuntaria? ¿Acaso el cambio de discurso del gobierno y de los paramilitares fue una mera estrategia retórica, encaminada a producir efectos legitimadores? ¿O fue más bien el resultado de que los estándares jurídicos sobre derechos de las víctimas operaran como límites normativos de las opciones políticas disponibles para las negociaciones de paz? Como lo veremos en la siguiente sección, estas dos preguntas pueden recibir una respuesta parcialmente afirmativa, ya que corresponden a dos maneras distintas de entender el rol de la justicia transicional en las negociaciones de paz, a saber: el rol discursivo y el rol normativo de la justicia transicional en esos contextos.

37 Éste fue el caso, entre muchas otras, de las disposiciones relativas a los deberes de confesar y reparar de los victimarios a los que aludimos anteriormente.

38 Éste fue el caso de la disposición que estableció que el tiempo pasado en la zona de negociaciones de paz por los paramilitares podía ser sustraído del ya de por sí muy reducido castigo (de cinco a ocho años) que sería impuesto a los perpetradores de crímenes atroces. Según la Corte, esta disposición era inconstitucional, pues implicaba una afectación desproporcionada del derecho a la justicia de las víctimas, así como una ruptura del principio de equilibrio entre paz y justicia propio de la justicia transicional.

39 Por ejemplo, en el caso de la disposición de la ley de Justicia y Paz según la cual los victimarios tienen la obligación de confesar los crímenes en los que han participado, la Corte declaró su constitucionalidad, bajo la condición de que fuera interpretada en el sentido de que la confesión debe ser completa y fehaciente y que, si esos requisitos no son cumplidos, el victimario perderá el beneficio penal de castigo reducido en cualquier etapa del proceso. En el caso de las disposiciones de la ley relativas al deber del victimario de reparar a sus víctimas, la Corte las declaró constitucionales bajo la condición de que ese deber sea interpretado en el sentido de que implica la entrega de todos los bienes necesarios para reparar, incluidos tanto los obtenidos legalmente como los transferidos a terceros con el fin de evadir la responsabilidad. Además, la Corte estableció que el deber de los victimarios de reparar no se restringe a sus víctimas, sino que puede cubrir a aquellas víctimas del grupo al que pertenecían y que no pueden ser reparadas integralmente por sus victimarios directos, o bien porque éstos no han sido identificados, o bien porque no tienen bienes suficientes. Finalmente, la Corte declaró que el Estado mantiene una responsabilidad subsidiaria en relación con las reparaciones, que implica que, en caso de que los bienes de los victimarios sean insuficientes para reparar a las víctimas, el Estado tendrá que proveer el faltante que sea necesario para lograr una reparación integral. 


\section{El rol de la justicia transicional en negociaciones de paz}

En esta sección pretendemos analizar conceptualmente el rol que juega la justicia transicional en las negociaciones de paz. En nuestro concepto, se trata de una reflexión importante, que puede iluminar la compleja relación que existe entre el derecho y la política en esos contextos. Más aún, se trata de una reflexión muy útil para explicar el caso colombiano en el cual distintos actores con intereses distintos e incluso opuestos usan el discurso de la justicia transicional, y que puede ser extendida a otras situaciones similares. Para llevar a cabo esta reflexión, utilizaremos dos variables analíticas, que en nuestro parecer son apropiadas y útiles para comprender el rol que juega la justicia transicional en las negociaciones de paz.

La primera variable se enfoca en el discurso de la justicia transicional, y tiene el propósito de indagar sobre la manera como dicho discurso es usado, según los intereses que sirve. El uso de esta variable se basa en dos presuposiciones básicas. De un lado, la variable implica que no hay un uso unívoco, sino más bien varios usos posibles, del lenguaje y los mecanismos de la justicia transicional. En ese sentido, la variable se fundamenta en la idea de que el contenido de la justicia transicional es ambiguo o flexible, de tal forma que puede ser interpretado -e incluso manipulado- de diferentes maneras. De otro, el uso de esta variable implica que las diferentes maneras en las cuales puede interpretarse y en consecuencia utilizarse el discurso de la justicia transicional dependen de los intereses de los actores que lo usan. Dado que estos intereses son distintos e incluso pueden ser contradictorios, la variable implica también que los actores que usan el discurso de la justicia transicional luchan o compiten por su significado y contenido, y que la imposición de un significado determinado como aquél que es dominante o hegemónico es el resultado de una distribución desigual de poder entre los actores.

La segunda variable a través de la cual puede analizarse el rol de la justicia transicional en las negociaciones de paz se enfoca en la relación entre paz y justicia, que está a la base de cualquier concepción de justicia transicional. Como lo mencionamos anteriormente, esta relación hace referencia a la relación más abstracta entre el derecho y la política y, en el caso de las negociaciones de paz, consiste en la relación entre los estándares jurídicos sobre derechos de las víctimas y las dinámicas políticas de las negociaciones. El uso de esta variable tiene el propósito de analizar las diferentes maneras en las cuales esta relación entre paz y justicia, o entre la política (negociaciones) y el derecho (estándares jurídicos), puede ser comprendida o interpretada. Así, la variable se basa en la presuposición de que hay, en efecto, algún tipo de distinción entre la política y el derecho, cuya existencia permite un análisis de la relación entre ambos. Esta presuposición implica rechazar la idea de que el derecho en general, y los estándares jurídicos de la justicia transicional en particular, sólo son discursos, cuya naturaleza no puede distinguirse de aquélla de la política de ninguna manera. Por consiguiente, al usar esta variable se asume que, aunque puede funcionar como un discurso susceptible de ser usado políticamente, la justicia transicional no se reduce a ese componente discursivo, sino que tiene también una faceta normativa. Esta asunción entraña la idea de que los estándares jurídicos de la justicia transicional tienen algún grado de dureza, lo cual permite que los mismos funcionen como una amenaza creíble, y da cuenta de su naturaleza normativa o imperativa. Es precisamente esta naturaleza aquello que permite que dichos estándares puedan distinguirse de la política en cierta medida.

Luego de haber anunciado su contenido básico y las presuposiciones en las que se basan, en lo que sigue pondremos estas dos variables analíticas en aplicación. Para cada una de las variables, desarrollaremos algunas reflexiones conceptuales y las ilustraremos a partir del caso colombiano. 


\section{A. Usos del discurso de la justicia transicional}

Es posible identificar al menos dos usos del discurso de la justicia transicional, que dependen de los diferentes intereses que puede servir, a saber: el uso manipulador y el uso democrático de la justicia transicional.

El primero consiste en el uso del discurso de la justicia transicional, y en particular de los derechos de las víctimas, con el principal propósito de ocultar la impunidad. Se trata de un uso manipulador, en la medida en que adopta el lenguaje de la justicia transicional como un instrumento meramente retórico, a través del cual no se realiza ninguna transformación material o práctica, pero sí se obtiene un importante efecto simbólico ${ }^{40}$. Este efecto simbólico consiste en la legitimación de las fórmulas para enfrentar un pasado de atrocidades que resultan de las dinámicas políticas de las negociaciones de paz, y que por lo general tienen como fin la impunidad, por ser el camino más fácil para lograr una paz negociada. Dichas fórmulas son diseñadas y acordadas haciendo caso omiso de los derechos de las víctimas y, como tal, son enteramente moldeadas por la política. Sin embargo, cuando se presentan como mecanismos de justicia transicional, aparecen como si estuvieran limitadas por e incluso sometidas a los estándares jurídicos que contienen esos derechos.

De esa manera, el discurso de la justicia transicional es manipulado con el fin de legitimar esas fórmulas de impunidad y, por esa vía, para perpetuar las relaciones desiguales de poder entre victimarios -que continúan beneficiándose de ellas- y víctimas -cuyos derechos permanecen desprotegidos $-{ }^{41}$. Cuando esto sucede, el uso del discurso de la justicia transicional no sólo es manipulador, sino también opresivo.

El segundo uso posible del discurso de la justicia transicional se caracteriza por su naturaleza democrática o emancipatoria. En efecto, en agudo contraste con el anterior, este uso de la justicia transicional tiene el propósito de luchar contra la impunidad. Dado que los mecanismos de la justicia transicional, y en especial los derechos de las víctimas a la verdad, la justicia y la reparación, son concebidos como herramientas para lograr ese propósito ${ }^{42}$, el uso democrático de dicho discurso consiste precisamente en reclamar la aplicación efectiva de estos mecanismos. Por tanto, este uso democrático tiene el objetivo de trascender el contenido meramente retórico de la justicia transicional para, de esa manera, hacerlo eficaz instrumentalmente -y no sólo en forma simbólica-. En ese sentido, el uso democrático del discurso de la justicia transicional se toma en

40 Sobre el efecto simbólico o legitimador del discurso en general, ver, por todos, Bourdieu, P. 2001. "Las formas de capital", en Poder, derecho y clases sociales, Bilbao: Desclée de Brower, Capítulo IV. Sobre la eficacia simbólica del derecho en particular, ver García Villegas, M. 1994. La eficacia simbólica del derecho. Bogotá: Ediciones Uniandes; Bourdieu, P. 2000. La fuerza del derecho. Bogotá: Uniandes.

41 Sobre las relaciones desiguales de poder entre víctimas y victimarios, ver Gómez-Müller, A. 2007. “Olvido, ideología y memoria", Conferencia presentada en el seminario Reconstrucción de Colombia, Ob. Cit.

42 De hecho, el reciente reconocimiento internacional de la verdad, la justicia y la reparación como derechos subjetivos de las víctimas de atrocidades es comprendido de mejor manera si se lo ve como una respuesta a la lucha incansable de los movimientos de víctimas y de derechos humanos contra la impunidad. Sin duda, América Latina ha sido uno de los escenarios más importantes para estos desarrollos. Así, por ejemplo, la lucha de los movimientos de víctimas y de derechos humanos de Chile y Argentina contra la impunidad de los crímenes cometidos por regímenes autoritarios condujo a los primeros reconocimientos internacionales de los derechos de las víctimas por parte de la Comisión Interamericana de Derechos Humanos. En los años ochenta, estos reconocimientos trajeron como resultado acuerdos amistosos entre los gobiernos y las víctimas. Un ejemplo más reciente puede ser hallado en la experiencia de Perú, en donde la lucha de los movimientos de víctimas y de derechos humanos contra la impunidad, y en particular contra las leyes de amnistía, produjo la famosa decisión de la Corte Interamericana de Derechos Humanos sobre el caso Barrios Altos, en la cual los derechos de las víctimas fueron reconocidos explícitamente como derechos humanos de aplicación directa, y las leyes de amnistía fueron declaradas contrarias a los mismos. Corte Interamericana de Derechos Humanos, Caso Barrios Altos, sentencia de marzo 14 de 2001, serie C No 75. 
serio su contenido; para ello le confiere una dimensión normativa o jurídicamente obligatoria, que puede funcionar como un límite a las fórmulas para enfrentar el pasado que resultan de las dinámicas políticas de las negociaciones de paz.

Se trata de un uso democrático de la justicia transicional porque tiene el propósito de dar fin a la impunidad a través de la materialización de los derechos de las víctimas y, al hacerlo, busca lograr el reconocimiento y la efectiva protección de los derechos humanos en contextos en los cuales estos derechos han sido violados masiva y sistemáticamente. Más aún, el proceso de uso del discurso de la justicia transicional de esta manera es, en sí mismo, no sólo democrático sino también emancipatorio, ya que trae como resultado el empoderamiento de las víctimas de violaciones de derechos humanos. Este empoderamiento es crucial para lograr una transformación de las relaciones asimétricas de poder entre víctimas y victimarios, ya que ayuda a reconstruir la identidad de las víctimas como sujetos morales y políticos con derechos, identidad que con frecuencia es perdida como consecuencia de su sometimiento a graves violaciones de derechos humanos.

Las dos formas de usar el discurso de la justicia transicional anteriormente descritas pueden ser identificadas en el actual contexto colombiano. En efecto, la existencia de estos dos posibles usos del discurso ayuda a explicar, en alguna medida, el hecho paradójico de que, en un contexto en el cual no está teniendo lugar ninguna transición, la mayoría de actores políticos usen el lenguaje de la justicia transicional, a pesar de tener intereses y propósitos radicalmente distintos e incluso contradictorios. En Colombia, en el marco de las negociaciones de paz entre el gobierno y los paramilitares, el discurso de la justicia transicional es usado, a un mismo tiempo, como mecanismo para ocultar la impunidad y como instrumento para luchar contra la impunidad.

El uso manipulador de la justicia transicional es hecho esencialmente por el gobierno y los líderes paramilitares, pero también es ampliamente apoyado por la mayoría de la sociedad civil. Este uso consiste en utilizar una retórica generosa de la verdad, la justicia y la reparación, con el fin de ocultar y legitimar procesos parciales de impunidad. Las ilustraciones más prominentes de este uso manipulador de la justicia transicional pueden encontrarse en el texto original de la ley de Justicia y Paz y en los decretos reglamentarios de la misma, expedidos por el gobierno después de la sentencia C-370 de 2006 de la Corte Constitucional.

Como lo mencionamos en la sección anterior de este artículo, el proyecto de ley de lo que después se convirtió en la ley de Justicia y Paz fue presentado en el Congreso por el gobierno después del fracaso de su primera propuesta de marco jurídico para enfrentar las atrocidades cometidas por los paramilitares desmovilizados. El hecho de que el proyecto de ley anterior no contuviera ni una sola referencia a los mecanismos de la justicia transicional -y en particular a los derechos de las víctimas-, unido al hecho de que el cambio al discurso de la justicia transicional fue intempestivo y pudo realizarse sin ninguna resistencia de parte de los paramilitares, operan como indicios importantes de la naturaleza meramente retórica de dicho cambio.

Como quiera que sea, el texto original de la ley de Justicia y Paz es un ejemplo claro de un uso manipulador de la justicia transicional. En efecto, aunque las declaraciones de principio de la ley en materia de verdad, justicia y reparación eran muy generosas, las mismas no venían acompañadas de mecanismos institucionales adecuados para materializar tales derechos de manera suficiente $^{43}$. Por ello, se trataba de una ley que era ampliamente reconocida por su generosidad

\footnotetext{
43 Como lo mencionamos anteriormente, algunas de las falencias principales de la ley de Justicia y Paz para proteger los derechos de las víctimas tenían que ver con (i) la admisión de la posibilidad de sustraer del ya de por sí muy reducido castigo aplicable a los desmovilizados que han cometido crímenes atroces el tiempo pasado por ellos en la zona de negociación de paz; (ii) el hecho de que las confesiones incompletas o falsas de los paramilitares no implicaban la pérdida de beneficios penales, (iii) y la restricción del deber de reparar únicamente a los bienes obtenidos ilegalmente y aún poseídos por los paramilitares.
} 
en la protección de los derechos de las víctimas ${ }^{44}$, pero cuya aplicación llevaría inexorablemente a una carencia de protección de esos derechos. Quizá por eso los líderes paramilitares nunca criticaron la ley de Justicia y Paz y, en cambio, cuando la Corte Constitucional expidió la sentencia C-370 de 2006 y declaró en ella la inconstitucionalidad y la constitucionalidad condicionada de muchas de sus disposiciones, defendieron su texto como un compromiso vinculante adquirido por el Estado ${ }^{45}$.

Como respuesta a las fuertes reacciones de los paramilitares ante la decisión de la Corte -que incluyeron la amenaza de abandonar el proceso de paz, la cual fue puesta en práctica por algunos líderes como Vicente Castaño-, el gobierno ha hecho varios esfuerzos por ir en contra de la sentencia a través de la expedición de una serie de decretos reglamentarios ${ }^{46}$. Sin duda, estos decretos constituyen la ilustración más evidente del uso manipulador de la justicia transicional por el gobierno, movido por la presión de los paramilitares. De hecho, a través de esos decretos, el gobierno ha tratado de regresar al texto original de la ley de Justicia y Paz, es decir, a la etapa del proceso en la cual la justicia transicional, y en particular los derechos de las víctimas, funcionaban como herramientas para legitimar procesos parciales de impunidad, y no como normas jurídicas efectivamente aplicables -como lo ha requerido la decisión de la Corte que lo sean-.

Vistos en conjunto, los acontecimientos anteriores podrían ser interpretados de la siguiente manera: las negociaciones de paz entre el gobierno y los líderes paramilitares -cuyo contenido concreto nunca se conoció porque fue mantenido en secreto- favorecieron una estrategia jurídica de evasión de la justicia retributiva, a través del uso de las categorías de la justicia restaurativa, y particularmente de las nociones de reconciliación y perdón. Sin embargo, dado que esta estrategia se enfrentó rápidamente a importantes resistencias políticas y jurídicas, las negociaciones de paz escogieron la manipulación del discurso de la justicia transicional como nueva estrategia para lograr el mismo objetivo de impunidad. Esta estrategia comenzó promoviendo un texto legal cuya retórica era favorable a los derechos de las víctimas, pero cuya implementación admitiría la continuidad de procesos parciales de impunidad. Y, una vez dicho texto fue transformado como consecuencia de la decisión de la Corte Constitucional, la estrategia se convirtió en la evasión de su aplicación, a través del uso (o más bien el abuso) de la competencia del gobierno de reglamentar normas.

Ciertamente, es difícil probar o siquiera poner a prueba esta interpretación, pues los únicos que saben cuáles fueron las estrategias o fórmulas acordadas en las negociaciones de paz son los

44 Uno de los mejores ejemplos de este reconocimiento es el comentario supuestamente hecho por Luis Moreno -Fiscal General de la Corte Penal Internacional- a Eduardo Pizarro -Presidente de la CNRR-, según el cual la ley de Justicia y Paz es la primera experiencia a nivel mundial de buscar la paz a través de la aplicación de justicia. Pizarro cita con frecuencia este comentario tanto en conferencias públicas como en artículos de periódico. Ver, por ejemplo, Pizarro, E. 2006, Conferencia con ocasión del Coloquio Internacional Reparaciones a las víctimas en Colombia y Perú: Retos y perspectivas. Bogotá: Alianza Francesa, diciembre de 2006, disponible en: www.pucp.edu.pe/idehpucp//images/docs/ ponencia\%20de\%20eduardo\%20pizarro.doc.

45 Al respecto, ver Bergsmo y Kalmanovitz, Ob. Cit.

46 Éste es particularmente el caso de los decretos reglamentarios No 3391 y 4436 de 2006. Entre muchos otros asuntos, a través de estos decretos el gobierno contravino la decisión de la Corte Constitucional de declarar la inconstitucionalidad de la norma que permitía sustraer el tiempo pasado por los paramilitares en la zona de negociación del castigo penal aplicable a sus atrocidades, así como de la norma que definía la conformación y participación de grupos paramilitares como delito de sedición $-y$, por ende, como delito político susceptible de ser indultado o amnistiado-. En ambos casos, con el fin de mantener vivas las disposiciones inconstitucionales, el gobierno alegó que, en virtud del principio de favorabilidad, la decisión de la Corte sólo debería aplicarse a los paramilitares que se desmovilizaron con anterioridad a la misma, a pesar de que la mayoría de paramilitares se desmovilizó antes. 
negociadores mismos. No obstante, parece ser una interpretación razonable, no sólo porque los acontecimientos antes narrados encajan perfectamente en ella, sino también porque ayuda a explicar el hecho de que, a pesar de todos los cambios sufridos por el marco jurídico -muchos de los cuales evidentemente han afectado a los paramilitares-, los líderes paramilitares no han roto -y probablemente no romperán- las negociaciones de paz.

Con independencia de que esta interpretación sea o no admitida, lo cierto es que hay abundantes pruebas del uso manipulador de la justicia transicional por el gobierno y los paramilitares. Más aún, éste parece ser el uso dominante o hegemónico de la justicia transicional en el contexto político colombiano no sólo por el poder que efectivamente ostentan quienes lo llevan a cabo, sino también porque éstos han logrado exitosamente ponerlo en práctica, y la mayoría de la sociedad civil lo ha consentido implícitamente. En efecto, con excepción de una muy pequeña minoría, la opinión pública no ha sido particularmente crítica de la manera como el gobierno ha desarrollado las negociaciones de paz con los paramilitares. Al contrario, como lo muestra una encuesta reciente publicada por la Revista Semana, a pesar de que el 38\% de la población cree que el Presidente de la República sostuvo acuerdos ilegales con los paramilitares, el 75\% de la población percibe positivamente al mandatario. Además, no parece haber una percepción generalizada de la necesidad de castigar a los paramilitares. Como también lo muestra dicha encuesta, para el 25\% de la población, la existencia de los grupos paramilitares se justifica, para el $33 \%$ ésta es necesaria para combatir a los grupos guerrilleros, y para el 32\% el Estado no debería combatir a los grupos paramilitares ${ }^{47}$.

Sin embargo, el discurso de la justicia transicional no sólo ha sido usado de manera manipuladora en Colombia. También es posible identificar usos democráticos de dicho discurso que, a pesar de ser promovidos por una minoría, tienen efectos muy importantes. Esta minoría está compuesta esencialmente por organizaciones de derechos humanos, movimientos de víctimas, la Corte Constitucional, la Corte Suprema de Justicia y la Corte Interamericana de Derechos Humanos. El uso democrático del discurso de la justicia transicional emprendido por estos actores ha consistido en tomarse en serio los derechos de las víctimas y la garantía de no repetición, con el fin de combatir la impunidad. De esa manera, se ha tratado de una lucha por la eficacia real del contenido jurídico de la justicia transicional, y en contra de sus efectos meramente legitimadores. Los ejemplos más notorios de este uso democrático de la justicia transicional pueden hallarse en los diversos ataques tanto del discurso político como del marco jurídico defendidos por el gobierno en relación con el proceso de desmovilización, en el uso de ese marco jurídico de maneras emancipatorias tanto por las organizaciones de la sociedad civil como por los jueces, y en la producción de propuestas "desde abajo" 48 de mecanismos para la satisfacción de los derechos de las víctimas y para asegurar la no repetición de las atrocidades.

A lo largo del proceso de desmovilización, los movimientos de víctimas y las organizaciones de derechos humanos han criticado de manera muy articulada el discurso político defendido

\footnotetext{
47 "La gran encuesta de la parapolítica", Ob. Cit.

48 El concepto "desde abajo" hace referencia a una propuesta teórica de acuerdo con la cual los análisis sociológicos y sociojurídicos deberían incluir la perspectiva de las comunidades locales y de los miembros de la sociedad civil que carecen de poder. De acuerdo con esta propuesta, los análisis tradicionales se quedan cortos porque no tienen en cuenta los puntos de vista y las iniciativas de estos actores como objetos de estudio relevantes, sino que se enfocan en las instituciones estatales y en los miembros de la élite, esto es, en los actores e iniciativas "desde arriba". Los autores que defienden esta propuesta tienden a establecer una correspondencia entre las perspectivas hegemónicas y los actores desde arriba, e igualmente entre las perspectivas contra-hegemónicas y los actores desde abajo. Ver, entre otros, Santos de Sousa, B. Ob. Cit; Santos de Sousa, B. y Rodríguez, C. (eds.). 2005. Law and Globalization from Below: Towards a Cosmopolitan Legality. Cambridge: Cambridge University Press; Rajagopal, B. 2003. International Law from Below. Development, Social Movements and Third World Resistance. Cambridge: Cambridge University Press.
} 
por el gobierno. Un buen ejemplo de ese ataque es ofrecido por la lucha emprendida por esas organizaciones en contra de la noción de reconciliación, ampliamente usada (y abusada) por el gobierno y por otros sectores sociales como la iglesia y los paramilitares desmovilizados. El gobierno usa persistentemente esta noción para justificar la conveniencia de aplicar el paradigma de la justicia restaurativa a la situación colombiana ${ }^{49}$, lo cual implica la exclusión de fórmulas de justicia retributiva y el establecimiento de vínculos estrechos entre víctimas y victimarios ${ }^{50}$. Para ello, el gobierno acude a una definición maximalista o fundamentalista de la reconciliación, de conformidad con la cual ésta exige que todos los ciudadanos establezcan entre sí estrechos vínculos de solidaridad y simpatía, y en particular que las víctimas perdonen a sus victimarios y estén dispuestas a crear vínculos de esa naturaleza con ellos.

Los movimientos de víctimas y las organizaciones de derechos humanos han criticado arduamente esta noción por imponer formas forzadas de reconciliación, que van en contra de los derechos de las víctimas a la justicia, a la autonomía y a la dignidad, y que resultan antidemocráticas. En efecto, si la reconciliación es comprendida de una manera tan gruesa ${ }^{51}$, todos aquellos que no estén de acuerdo con ella pueden ser vistos como un obstáculo a la reconciliación y a la paz. En el caso particular de las víctimas, aunque la decisión de perdonar corresponde exclusivamente al ámbito moral -no al jurídico-, esta visión de la reconciliación no les deja una opción distinta de aceptar perdonar a sus victimarios, a pesar de que este perdón forzado pueda violar sus derechos e incluso crear resentimientos que puedan convertirse en un obstáculo a la paz. Es por eso que los movimientos de víctimas y las organizaciones de derechos humanos han propuesto interpretaciones alternativas de la noción de reconciliación, que pueden ser compatibles con la democracia y los derechos de las víctimas, en particular a través de la garantía del derecho a disentir y de la posibilidad de no perdonar. De acuerdo con estas interpretaciones, el perdón no es necesario para lograr una reconciliación social; basta con asegurar el reconocimiento de todos los miembros de la sociedad -incluidos los antiguos enemigos- como conciudadanos.

La crítica de la noción de reconciliación utilizada por el gobierno y la defensa de esta interpretación alternativa han tenido efectos democráticos significativos. De una parte, esta crítica y esta defensa han apoyado la idea de que disentir y no perdonar a los victimarios constituyen opciones válidas que no van necesariamente en contra de la paz y la reconciliación, lo cual ha implicado un empoderamiento de las víctimas. De otra parte, este uso democrático de la justicia transicional y de los derechos de las víctimas se ha traducido en un ataque político y jurídico de las disposiciones jurídicas que contienen la criticada noción de reconciliación ${ }^{52}$. Aunque muchos de estos ataques todavía no han producido efectos, el retiro del proyecto de ley de Alternatividad penal es un buen primer ejemplo de su éxito.

49 Para una crítica al uso de la justicia restaurativa como paradigma dominante de la justicia transicional en general, y de la situación colombiana en particular, ver Uprimny, R. y Saffon, MP. "Justicia transicional y justicia restaurativa: tensiones y complementariedades", en Uprimny, Botero, Restrepo y Saffon, Ob. Cit.

${ }^{50}$ Con base en la perspectiva restaurativa, el gobierno ha defendido fórmulas jurídicas muy problemáticas. Así, como lo mencionamos previamente, el gobierno propuso el proyecto de ley de Alternatividad Penal, que excluía el castigo penal de los desmovilizados incluso si habían cometido crímenes atroces. Más recientemente, a través del decreto reglamentario № 3391 de 2006, el gobierno creó los llamados "proyectos productivos", en los que se espera que las víctimas trabajen en conjunto con los perpetradores, compartan las utilidades con ellos, y perciban esas utilidades como una reparación.

51 Esta expresión es utilizada por David Crocker en: Crocker, D. 2002. "Democracy and Punishment: Punishment, Reconciliation, and Democratic Deliberation," Buffalo Criminal Law Review, No.5, pp. 509-49.

52 Tal es el caso del proyecto de ley de Alternatividad Penal -que fue atacado políticamente en el Congreso-, del decreto № 3391 de 2006 -que fue demandado por nulidad ante el Consejo de Estado por la Comisión Colombiana de Juristas y muchas otras organizaciones-, y de las disposiciones de la ley de Justicia y Paz que se refieren a la noción de reconciliación - que fueron recientemente demandadas por inconstitucionalidad ante la Corte Constitucional por muchas organizaciones no gubernamentales-. 
La noción de reconciliación no ha sido el único blanco de los ataques políticos y jurídicos emprendidos por los movimientos de víctimas y las organizaciones de derechos humanos. Éstos han seguido de cerca la discusión y las propuestas de fórmulas jurídicas para enfrentar las atrocidades cometidas por los paramilitares, y las han criticado siempre que van en contra de los derechos de las víctimas o que ponen en riesgo la garantía de no repetición. El ejemplo más notorio de estos esfuerzos es la batalla jurídica que estos movimientos y organizaciones han emprendido enérgicamente contra el texto original de la ley de Justicia y Paz. Esta batalla ha consistido en un riguroso escrutinio del texto para identificar las falencias que contiene en términos de protección de los derechos de las víctimas, y en la consecuente presentación de múltiples acciones de inconstitucionalidad en su contra, en las que esencialmente se defiende una efectiva protección de tales derechos y se critica la ruptura del equilibrio entre justicia y paz propio de la justicia transicional ${ }^{53}$.

El ataque de la ley de Justicia y Paz por parte de estos movimientos y organizaciones no ha producido efectos completamente exitosos, si se tiene en cuenta que la Corte Constitucional no accedió a su petición inicial, consistente en la declaratoria de inconstitucionalidad de la totalidad de la ley ${ }^{54}$. Sin embargo, se trata en todo caso de efectos bastante importantes, pues la Corte Constitucional ha declarado la inconstitucionalidad y la constitucionalidad condicionada de muchas disposiciones de la ley que afectaban desproporcionadamente los derechos de las víctimas ${ }^{55}$. Estas decisiones de la Corte constituyen, ellas mismas, otro uso democrático del discurso de la justicia transicional. En efecto, como lo mencionamos anteriormente, las mismas se fundamentan en el principio propio de la justicia transicional que establece la necesidad de lograr un equilibrio entre la paz y la justicia, que implica que los derechos de las víctimas pueden ser restringidos pero no sacrificados desproporcionadamente en favor de la paz. De ese modo, las sentencias de la Corte han apuntado a proteger efectivamente los derechos de las víctimas y a restringir las fórmulas jurídicas que conducen a la impunidad.

La Corte Constitucional no ha sido la única institución estatal que ha hecho un uso democrático del lenguaje y los mecanismos de la justicia transicional. Otro ejemplo importante (aunque no el único a nivel nacional) $)^{56}$ es ofrecido por la valiente labor emprendida recientemente por la Corte Suprema de Justicia de investigar penalmente a los congresistas que han sostenido vínculos con grupos paramilitares, y que hasta el momento ha producido la detención de decenas de esos altos funcionarios. Esta labor resulta esencial para combatir la impunidad y para garantizar la no repetición de las atrocidades porque contribuye al desmonte de las estructuras de poder político de los paramilitares y a la depuración de las instituciones oficiales.

Además de los ejemplos de las Cortes Constitucional y Suprema, es menester reconocer el importante uso democrático de la justicia transicional que ha realizado otro tribunal, en este caso de carácter supranacional: la Corte Interamericana de Derechos Humanos. A través de sus cinco sentencias de condena del Estado colombiano por las masacres cometidas por grupos paramilitares

53 El resumen de cada una de las acciones de inconstitucionalidad presentadas contra la ley de Justicia y Paz puede encontrarse en las sentencias de la Corte que han sido promovidas por esas acciones. Ver Corte Constitucional, sentencias C-127 de 2006, C-319 de 2006, C-370 de 2006, C-455 de 2006, C-531 de 2006, C-575 de 2006, C-650 de 2006, C-670 de 2006, C-719 de 2006, C-080 de 2007.

54 Para los argumentos que apoyaron esta solicitud, ver Corte Constitucional, sentencia C-370 de 2006, que incluye un resumen de la primera acción de inconstitucionalidad presentada contra la ley.

55 Ver Corte Constitucional, sentencias C-127 de 2006, C-319 de 2006, C-370 de 2006, C-455 de 2006, C-531 de 2006 , C-575 de 2006, C-650 de 2006, C-670 de 2006, C-719 de 2006, C-080 de 2007.

56 Órganos de control como la Procuraduría General de la Nación también han actuado en favor de la aplicación efectiva de los derechos de las víctimas. 
con la omisión y/o complicidad de agentes del Estado ${ }^{57}$, la Corte Interamericana ha jugado un rol activo en la elucidación de la verdad sobre el paramilitarismo en general, y sobre la colusión de sus miembros con agentes estatales en particular. El esclarecimiento de la verdad de tales fenómenos resulta esencial para materializar no sólo los derechos a la verdad, la justicia y la reparación de las víctimas que se han dirigido a la Corte ${ }^{58}$, sino también para satisfacer el derecho colectivo de la sociedad colombiana como un todo a conocer la verdad de las atrocidades pasadas ${ }^{59}$. Por ello, esta reconstrucción judicial de la verdad constituye un mecanismo fundamental de uso democrático de los derechos de las víctimas.

Pero la elucidación de la verdad del fenómeno paramilitar no ha sido la única vía a través de la cual la Corte Interamericana ha hecho un uso democrático de la justicia transicional. En el caso de la masacre de La Rochela, su sentencia más reciente sobre el paramilitarismo en Colombia, la Corte se refirió expresamente al marco jurídico actualmente utilizado para enfrentar las atrocidades cometidas por el paramilitarismo. Aunque no realizó un análisis detallado de ese marco jurídico -como se lo habían solicitado los demandantes-, la Corte sí afirmó que si bien el equilibrio entre justicia y paz podía ser buscado, el mismo no podía utilizarse como mecanismo para producir una impunidad de facto. De esa manera, la Corte Interamericana impuso un límite claro a los esfuerzos del Estado colombiano por lograr la paz con los paramilitares: la imposibilidad de conducir a la impunidad a través de la aplicación de estándares jurídicos sobre derechos de las víctimas aparentemente aceptables. Al hacerlo, la Corte hizo un uso democrático del discurso de la justicia transicional.

Los anteriores ejemplos muestran que los agentes "desde arriba" 60 , incluyendo instituciones estatales y supraestatales, también pueden llevar a cabo un uso democrático de la justicia transicional. Así, estos ejemplos son útiles para cuestionar la idea de que las prácticas emancipatorias sólo vienen desde abajo ${ }^{61}$. A pesar de ello, es innegable que la mayoría de prácticas democráticas o emancipatorias en general, y de los usos democráticos de la justicia transicional en particular, vienen desde abajo.

Además de los ejemplos mencionados, una ilustración significativa de esos usos puede encontrarse en las iniciativas y propuestas comunitarias o locales sobre cómo proteger los derechos de las víctimas a la verdad, la justicia y la reparación, y asegurar la garantía de no repetición. Para sólo mencionar una de muchas iniciativas de esa naturaleza ${ }^{62}$, un buen ejemplo es la propuesta

57 Corte Interamericana de Derechos Humanos, Caso de la masacre de 19 Comerciantes vs. Colombia, sentencia de julio 5, 2004, serie C № 109; Caso de la masacre de Mapiripán vs. Colombia, sentencia de septiembre 15, 2005, serie C № 134; Caso de la masacre de Pueblo Bello, sentencia de enero 31, 2006, serie C № 140; Caso de las masacres de Ituango vs. Colombia, sentencia de julio 1, 2006, serie C No 149; Caso de la masacre de La Rochela vs. Colombia, sentencia de mayo 11, 2007, serie C No 163 .

58 En efecto, a través de la elucidación de la verdad sobre la omisión y/o colusión de agentes estatales respecto de atrocidades cometidas por los paramilitares, la Corte Interamericana de Derechos Humanos ha logrado establecer una doctrina según la cual el Estado puede ser declarado responsable internacionalmente por acciones de terceros. Es así como la Corte ha logrado condenar al Estado colombiano a pagar reparaciones a las víctimas de masacres cometidas por grupos paramilitares. Ver id.

59 Para un análisis de las sentencias de la Corte Interamericana de Derechos Humanos como mecanismo para construir una narrativa sobre las atrocidades en Colombia, ver Saffon, MP y Uprimny, R. 2007. "Las masacres de Ituango contra Colombia: Una sentencia de desarrollo incremental", Revista CEIIL: Debates sobre Derechos Humanos y el Sistema Interamericano $\mathrm{N}^{\circ} 3$.

60 Para este concepto ver supra nota 50.

61 En nuestro concepto, esta idea es defendida por Boaventura de Sousa Santos. Ver Santos de Sousa, Ob. Cit.

62 Para otro ejemplo ilustrativo de una iniciativa desde abajo en materia de verdad y reconciliación, ver el caso del nororiente antioqueño narrado por Catalina Díaz en: Díaz, C. 2007. "Challenging Impunity from Below: The Contested Ownership of Transitional Justice in Colombia", Forthcoming publication. 
de reforma de la Constitución presentada al Congreso por el Movimiento Nacional de Víctimas de Crímenes de Estado, consistente en la inclusión de la verdad, la justicia, la reparación y la garantía de no repetición como derechos fundamentales, y en el establecimiento de algunos mecanismos para lograr la materialización de esta garantía ${ }^{63}$. Esta iniciativa constituye un evidente uso democrático de la justicia transicional, ya que insiste en la aplicabilidad directa y en el carácter fundamental de los derechos de las víctimas, así como en la importancia de garantizar la sostenibilidad de la paz. Sin embargo, se trata de una iniciativa que aún dista mucho de ser exitosa, pues hasta el momento no ha encontrado mayor apoyo en el Congreso.

En conclusión, el uso manipulador de la justicia transicional como instrumento de impunidad predomina en Colombia. Como resultado, el derecho, y en especial los estándares jurídicos en materia de derechos de las víctimas parecen estar dominados por la dinámica política. Es por eso que no puede sobrestimarse la potencialidad de la justicia transicional para funcionar como herramienta de transformación social. En particular, debería existir escepticismo frente a la posibilidad de lograr una transformación completa del uso hegemónico del discurso de la justicia transicional y, con ello, el establecimiento de restricciones jurídicas a la política de las negociaciones de paz. No obstante, en nuestro concepto, es crucial reconocer el valor de los usos democráticos de la justicia transicional. Aunque son realizados por una minoría de la sociedad y han logrado cambios marginales del marco jurídico de las negociaciones de paz, estos usos han producido efectos muy importantes.

De hecho, por primera vez en Colombia, los derechos de las víctimas están al centro de todas las discusiones políticas y jurídicas relativas a la pregunta sobre cómo enfrentar las atrocidades cometidas en el pasado. Esto también ha traído como resultado el reconocimiento de las víctimas como actores políticos relevantes con quienes deberían discutirse todos los asuntos relacionados con esta pregunta. Por inocuo que pueda parecer, esto constituye un cambio radical en la dinámica política colombiana, en la cual la perspectiva, las necesidades y los intereses de las víctimas no habían sido tenidos en cuenta nunca antes. Más aún, este cambio ha contribuido al empoderamiento de las víctimas, al fortalecimiento de sus movimientos y al establecimiento de importantes redes transnacionales con ONGs internacionales, todos los cuales son elementos esenciales para lograr la transformación de las relaciones desiguales de poder entre víctimas y victimarios. Finalmente, los usos democráticos de la justicia transicional también han producido algunos resultados concretos en la reforma del marco jurídico existente para enfrentar las atrocidades. Aunque menores si se los compara con la tendencia general a hacer un uso manipulador de la justicia transicional, estos resultados constituyen pequeñas victorias, que resultan muy importantes en medio de un contexto tan adverso para la protección de los derechos de las víctimas.

\section{B. La relación entre paz y justicia}

La segunda variable analítica a través de la cual puede estudiarse el rol jugado por la justicia transicional en negociaciones de paz hace énfasis en las formas en las cuales puede interpretarse la relación entre los valores de paz y justicia, o entre las dinámicas políticas de las negociaciones de paz (la política) y los estándares jurídicos de la justicia transicional (el derecho). En nuestro concepto, además de la visión tradicional de esta relación, que ve en ella una tensión inevitable entre paz y justicia, existe una visión alternativa y complementaria, según la cual los estándares jurídicos de la justicia transicional pueden funcionar como restricciones virtuosas que moldean las dinámicas políticas de las negociaciones de paz.

63 Tales mecanismos incluyen la prohibición constitucional de cualquier tipo de delegación del uso de armas a civiles por parte del Estado, y la obligación de depurar la fuerza pública. 
La visión tradicional de la relación entre justicia y paz identifica una tensión inevitable entre ambos valores. Según esta visión, la paz y la justicia son objetivos que halan en diferentes -y con frecuencia contradictorias- direcciones y, por esa razón, los mecanismos empleados para lograr una u otra tienden a ser opuestos, al menos en el corto plazo. Así, mientras que la impunidad es una herramienta importante para lograr la paz porque ofrece una atractiva razón para que los victimarios de atrocidades encuentren una solución negociada al conflicto, la imposición de justicia retributiva y la protección de los derechos de las víctimas son centrales para lograr la justicia. En ese sentido, la impunidad es vista como un obstáculo para realizar el valor de la justicia y, a la inversa, la protección de los derechos de las víctimas puede ser vista como un obstáculo para realizar el valor de la paz. En consecuencia, al menos en el corto plazo, la adopción de cualquier fórmula de justicia transicional implica necesariamente un sacrificio parcial o bien de la paz o bien de la justicia. Esta conclusión es vista como la ineludible tragedia de la justicia transicional.

Aunque la existencia de una tensión entre paz y justicia es innegable, existe una visión alternativa de la relación entre ambos valores, que complementa -en lugar de excluir- la interpretación antes descrita. De acuerdo con esta visión complementaria, la relación entre paz y justicia puede ser comprendida no sólo en términos de una tensión, sino también de una relación virtuosa. Esta última concepción consiste en admitir que los estándares jurídicos en materia de derechos de las víctimas pueden funcionar, no como obstáculos a las negociaciones de paz, sino más bien como restricciones virtuosas capaces de encauzar tales negociaciones. La admisión de esta posibilidad se basa en la asunción de que los estándares jurídicos sobre derechos de las víctimas constituyen un imperativo jurídico mínimo pero inescapable, que tienen un núcleo duro o no negociable y que, de ese modo, constituyen una amenaza creíble.

En un cierto sentido, si son claros y parecen muy difíciles de manipular o evadir, los estándares jurídicos pueden reducir la incertidumbre y disminuir el espectro de posibles resultados de un arreglo de paz, haciendo más fácil alcanzar un compromiso aceptable entre los intereses de actores antagonistas -en particular de victimarios y víctimas-. De hecho, si los estándares jurídicos sobre derechos de las víctimas son concebidos de esa manera, en virtud de los mismos, los actores de las negociaciones de paz pueden terminar cambiando sus posturas políticas iniciales hacia posiciones menos radicales, que pueden acercarse e incluso coincidir con aquéllas de otros actores con intereses y expectativas inicialmente opuestas. De esa forma, los estándares jurídicos en materia de derechos de las víctimas no funcionarían como obstáculos a la paz, sino más bien como restricciones virtuosas que encauzan las negociaciones de paz, mediante la restricción de las opciones políticas disponibles para enmarcarlas, y del acercamiento -hasta el punto de generar espacios consensuales- de los intereses y las expectativas de los diferentes actores.

Como lo indica Jon Elster, Monika Nalepa ha usado un razonamiento similar para explicar la expedición de leyes de depuración de la función pública en países postcomunistas de Europa del Este como Polonia y Hungría ${ }^{64}$. En esos países, fueron los propios postcomunistas los que promovieron la expedición de esas leyes mientras aún estaban en el poder, a pesar de que ellos y sus seguidores serían los destinatarios de las mismas. Según Nalepa, la promoción de estas leyes puede explicarse como una "movida preventiva", encaminada a evitar la expedición de leyes más severas por futuros gobiernos anticomunistas. En efecto, como los postcomunistas preveían que perderían el poder y que éste pasaría a manos de los anticomunistas, y sabían que en todo caso

64 Nalepa, M. 2003. "Suffer a Scratch to Avoid a Blow? When Post-Communists Hurt Themselves: A Model of Transitional Justice Legislation", en el momento manuscrito no publicado, Departamento de Ciencia Política, Universidad de Columbia, citado en: Elster, J. 2004. Closing the Books. Transitional Justice in Historical Perspective. Cambridge: Cambridge University Press, pp. 258-260. 
se expedirían leyes de depuración, optaron por promover leyes menos exigentes que aquéllas que hubieran sido promovidas por sus antagonistas.

Así las cosas, el que las leyes de depuración fuesen percibidas como inescapables y constituyeran una amenaza real para los postcomunistas produjo un cambio en las expectativas de estos actores y, como resultado, también en la postura política que tomaron. Como tenían la certeza de que inevitablemente se expedirían leyes de depuración, los postcomunistas no podían continuar manteniendo la postura según la cual esas leyes eran inadmisibles. Por consiguiente, decidieron defender una fórmula de castigo menos dura que, a su vez, fue aceptada por los anti-comunistas como una solución admisible. Y así fue como se creó un espacio consensual entre actores antagónicos.

Ese espacio consensual no podría haber existido si la amenaza de depuración no hubiese sido real. Por ende, lo que permite que los intereses y las expectativas de actores antagónicos se acerquen es la fuerza normativa de los estándares jurídicos de la justicia transicional -la obligación de depurar en el caso de Europa del Este; el requisito de satisfacer los derechos de las víctimas en un grado mínimo en el caso de Colombia-. En ausencia de dicha fuerza normativa, cada actor tiene intereses y expectativas enteramente distintos. Como resultado, es muy posible que se produzca un contexto de polarización, en el cual no existe la posibilidad de un encuentro de visiones. En contraste, cuando los estándares jurídicos son percibidos como restricciones normativas, es posible que los mismos puedan cambiar las expectativas de actores antagónicos, de tal forma que las mismas se acerquen. Este movimiento puede conducir a la creación de un espacio consensual en el cual, aunque los actores conservan intereses distintos, es posible que sus visiones se encuentren.

Podríamos intentar estilizar el argumento de la siguiente manera. Cuando los estándares jurídicos de la justicia transicional no son percibidos como límites normativos, prevalecen las posturas maximalistas entre los actores antagónicos. En efecto, todos los actores conciben que su punto de vista está justificado por principios y, por tanto, ninguno está dispuesto a ceder. En contraste, cuando los actores perciben esos estándares jurídicos como restricciones normativas, es posible que se muevan hacia posturas más flexibles, en las cuales ceden en sus principios en algún grado y, como resultado, se acercan a las posturas de sus antagonistas, incluso hasta el punto de compartir un espacio consensual con ellos. Por ejemplo, cuando los actores antagónicos son los victimarios y las víctimas -como es el caso de Colombia-, en ausencia de una percepción de los estándares jurídicos como restricciones inescapables, sus visiones serán completamente distintas y separadas, como resultado de su maximalismo. Así, mientras que los victimarios se concebirán a sí mismos en términos de una memoria heroica -en el caso de los paramilitares en Colombia, una memoria salvadora del país contra las guerrillas- y por ende creerán que el perdón y el olvido son la única manera de reconocer su participación heroica en el conflicto, las víctimas creerán que la aplicación rigurosa de los estándares jurídicos que contienen sus derechos es la única manera de dignificarlas -sin importar que haya negociaciones de paz en curso-. Estas posturas maximalistas implican polarización, pues el encuentro de las visiones de actores antagónicos no parece posible.

En contraste, si los victimarios perciben esos estándares jurídicos como restricciones normativas inescapables, la posibilidad de recibir una amnistía absoluta puede quedar excluida de su rango de expectativas. De esa manera, los victimarios podrían entrar en el rango de expectativas de las víctimas, como resultado de aceptar que sus derechos deben ser protegidos en algún grado. Por su parte, al ver que es posible lograr acuerdos con los victimarios en relación con los mecanismos para satisfacer sus derechos, las víctimas también podrían alejarse de su visión maximalista, y aceptar que sus derechos pueden ser limitados en algún grado. En ambos casos, los actores se moverían entonces de una postura principialista a una postura menos radical y más comprometida. Al hacerlo, 
entrarían a un espacio consensual, en el cual hay aún muchas opciones distintas para lograr un acuerdo entre los actores. Estas diferentes opciones pueden comprenderse como un espectro de posibilidades para satisfacer los derechos de las víctimas en el contexto de unas negociaciones de paz, que pueden estar más cerca o más lejos de los intereses de uno u otro actor.

Lo anterior podría esquematizarse de la siguiente manera:

\begin{tabular}{|l|l|}
\hline 1 & Perdón y olvido (maximalismo) \\
\hline 2 & $\begin{array}{l}\text { Aceptación retórica de la necesidad de proteger los derechos de las víctimas, pero ex- } \\
\text { clusión de la posibilidad de hacerlo en la práctica }\end{array}$ \\
\hline 3 & $\begin{array}{l}\text { Admisión de la posibilidad de satisfacer mínimamente la verdad y la reparación, pero } \\
\text { exclusión de cualquier forma de justicia punitiva }\end{array}$ \\
\hline 4 & $\begin{array}{l}\text { Admisión de un grado mínimo de justicia punitiva, junto con una mínima satisfacción } \\
\text { de la verdad y la reparación }\end{array}$ \\
\hline 5 & $\begin{array}{l}\text { Un grado mínimo de justicia punitiva, junto con una satisfacción plena de la verdad y } \\
\text { la reparación }\end{array}$ \\
\hline 6 & $\begin{array}{l}\text { Admisión de algún grado de restricción de los derechos de las víctimas, que no implica } \\
\text { una afectación desproporcionada de los mismos }\end{array}$ \\
\hline 7 & $\begin{array}{l}\text { Reclamo de protección total de los derechos de las víctimas, pero consideración de la } \\
\text { existencia de un contexto de negociaciones }\end{array}$ \\
\hline 8 & $\begin{array}{l}\text { Aplicación completa de los derechos de las víctimas, sin importar la existencia de nego- } \\
\text { ciaciones de paz (maximalismo) }\end{array}$ \\
\hline
\end{tabular}

Como puede verse, mientras que las filas 1 y 8 son polos en los cuales las visiones de los actores antagónicos no se encuentran de ninguna manera, las filas 2 a 7 implican un encuentro tal y constituyen las diferentes posibilidades en las que puede materializarse un acuerdo, algunas más cercanas a los intereses de los victimarios y otras a los intereses de las víctimas. Por más diferentes que sean, todas las posibilidades contenidas en las filas 2 a 7 implican un encuentro de las visiones de los perpetradores y las víctimas; por consiguiente, las mismas son el resultado de que los estándares jurídicos funcionen como restricciones virtuosas, esto es, como restricciones capaces de acercar visiones antagónicas entre sí.

Las dos formas antes analizadas de interpretar la relación entre paz y justicia, o entre las negociaciones políticas de paz y los estándares jurídicos de la justicia transicional, son útiles para comprender el actual contexto colombiano. De un lado, la interpretación según la cual existe una tensión irresoluble entre los valores de paz y justicia parece acertada para un contexto en el cual los actores armados que se desmovilizaron nunca fueron sometidos por el Estado, sino que decidieron voluntariamente negociar la paz. En un contexto tal, lo más posible es que esos actores condicionen la paz a la impunidad o, por lo menos a la imposición de una justicia no retributiva. Por tanto, hay una tensión inevitable entre la búsqueda de la paz y la justicia, al menos en el corto plazo.

Esto explica que esa interpretación de la relación entre paz y justicia sea utilizada frecuentemente en Colombia como una herramienta explicatoria de la situación del país. Aplicando la variable analítica que fue desarrollada en la sección anterior, el uso de esta interpretación puede tener un carácter tanto manipulador como democrático. En su primera faceta, la inevitable tensión entre paz y justicia es utilizada como un argumento para privilegiar la primera 
por sobre la segunda, al menos en las primeras etapas del proceso. Muchos analistas y actores políticos acuden a este argumento siempre que defienden ideas tales como la necesidad de lograr la paz antes de emprender la búsqueda de la justicia, la naturaleza de los derechos de las víctimas como obstáculos a la paz y la reconciliación, y la conveniencia de hacer flexibles estos derechos en favor de la paz ${ }^{65}$.

La interpretación de la relación entre paz y justicia en términos de una tensión inevitable también ha sido usada democráticamente en Colombia. En efecto, al admitir la existencia de esta tensión, pero al recordar a la vez la importancia de hallar un equilibrio entre los valores en conflicto, muchos han argumentado que la paz no puede ser empleada como una excusa para violar los derechos de las víctimas. Más aún, también han afirmado que, con frecuencia, la tensión entre paz y justicia sólo se presenta en el corto plazo, ya que la justicia puede ser concebida no como un obstáculo, sino más bien como un mecanismo extremadamente importante para lograr una paz durable y sostenible ${ }^{66}$.

De otro lado, la interpretación de la relación entre paz y justicia, según la cual la última puede funcionar como una restricción virtuosa de la primera, es útil para comprender el uso paradójico del discurso de la justicia transicional por la mayoría de actores en Colombia. De hecho, esta situación puede explicarse no sólo por los diferentes usos -manipuladores o democráticos-que pueden dársele a ese discurso, sino también por el poder normativo del discurso y, por ende, por la potencialidad de los estándares jurídicos de la justicia transicional de restringir las opciones políticas disponibles para lograr una paz negociada. Es entonces posible argumentar que el cambio intempestivo de discurso del gobierno y los paramilitares, que condujo a que éstos comenzaran a usar el lenguaje de la justicia transicional para defender la ley de Justicia y Paz, no fue únicamente el resultado de un uso manipulador de ese discurso por parte de esos actores, sino también una reacción a la constatación de que existe un imperativo jurídico mínimo e inescapable en relación con los derechos de las víctimas. La percepción de este imperativo mínimo como inescapable puede haber sido producida por la presión internacional y nacional de los movimientos de víctimas y las organizaciones de derechos humanos. Igualmente puede haber sido el resultado del actual entorno jurídico internacional -al que frecuentemente aluden las organizaciones de derechos humanos-, y en particular del inminente riesgo de intervención de la Corte Penal Internacional o de cualquier sistema judicial nacional en virtud del principio de jurisdicción universal, si la justicia no es garantizada adecuadamente ${ }^{67}$.

Como quiera que sea, la concepción de que los estándares jurídicos en materia de derechos de las víctimas tienen un núcleo duro del cual no pueden sustraerse los actores políticos cuando negocian la paz puede haber funcionado como una restricción virtuosa. En efecto, es posible sugerir que el cambio al discurso de la justicia transicional por parte del gobierno

\footnotetext{
65 Un buen ejemplo de esto es el proyecto de ley de Alternatividad penal, presentado originalmente por el gobierno al Congreso como una propuesta del marco jurídico para enfrentar las atrocidades cometidas por los paramilitares. El siguiente párrafo hacía parte de la defensa que el gobierno hizo del proyecto de ley en el Congreso: "La propuesta legislativa se orienta hacia una concepción restaurativa que supera la identificación de castigo con venganza, propia de un discurso en el que lo principal es reaccionar contra el delincuente con un dolor similar al que él produjo en la víctima y, sólo en segundo lugar, buscar la no repetición (prevención) y la reparación de las víctimas. Es importante tener en cuenta que al hacer justicia el derecho apunta hacia la reparación y no hacia la venganza. Ante la evidencia de que la pena privativa de la libertad, como única respuesta al delito, ha fracasado en muchas ocasiones en su cometido de lograr la resocialización de los delincuentes, el derecho penal contemporáneo ha avanzado en el tema de las sanciones alternativas" (Gaceta del Congreso No 436 de 2003).

66 Para esta línea argumentativa, ver Uprimny, Botero, Restrepo y Saffon, Ob. Cit.

67 Sobre las posibilidades de intervención de la Corte Penal Internacional y de aplicación del principio de jurisdicción internacional, ver Botero y Restrepo, Ob. Cit.
} 
y los paramilitares fue el resultado de su conciencia sobre el carácter vinculante y no negociable de un mínimo de protección de los derechos de las víctimas y, por consiguiente, de su preferencia por defender un castigo penal suave (como aquél contenido en la ley de Justicia y Paz), en lugar de enfrentar el riesgo de leyes futuras más severas. Según esta interpretación, este cambio acercó los intereses y expectativas del gobierno y los paramilitares a aquéllos de las víctimas, y permitió que surgiera un mínimo espacio de consenso entre ellos. Ese espacio consensual puede hallarse en la aceptación por parte de todos los actores de la imposibilidad de violar los derechos de las víctimas en favor de la paz, y en el paso de las víctimas al centro de las discusiones políticas.

Aplicando la tabla $N^{0} 1$ a la situación colombiana, podría concluirse que el cambio de los paramilitares y el gobierno al discurso de la justicia transicional los sacó de la columna 1, esto es, de la visión según la cual la única fórmula admisible era perdón y olvido. Al admitir (al menos retóricamente) la necesidad de proteger los derechos de las víctimas, esos actores se acercaron a las expectativas de las víctimas y, por ende, hicieron a éstas creer que existía la posibilidad de lograr acuerdos. Como resultado, las víctimas también se salieron de la columna 8 para pasar a una posición menos radical, según la cual era posible que un contexto de negociaciones de paz condujera a configuraciones menos protectoras de sus derechos.

Los anteriores movimientos han significado la entrada de ambos actores a un espacio consensual constituido por el reconocimiento de la imposibilidad de violar totalmente los derechos de las víctimas, representado por las filas 2 a 7 . Los movimientos de los actores de una columna a la otra han sido producidos por los cambios clave en los estándares jurídicos y, por esa vía, en las expectativas de esos actores. Sin embargo, esos cambios no han impedido de ninguna manera los usos manipuladores de la justicia transicional y de los derechos de las víctimas. En efecto, el gobierno y los paramilitares han intentado mantenerse en las primeras filas, que implican una aceptación retórica pero no real de la aplicabilidad de los derechos de las víctimas, incluso después de cambios fundamentales del marco jurídico tales como las decisiones de la Corte Constitucional de declarar la inconstitucionalidad y la constitucionalidad condicionada de muchas disposiciones de la ley de Justicia y Paz. Como lo mencionamos anteriormente, el gobierno y los paramilitares han intentado mantenerse en esta posición, a través del uso de decretos reglamentarios que van en contra de las decisiones de la Corte.

\section{Comentarios finales: hacia un uso cauteloso del discurso de la justicia transicional en Colombia}

En este artículo sostuvimos que el lenguaje y los mecanismos de la justicia transicional pueden ser usados de formas manipuladoras, es decir, como herramientas retóricas con el fin de ocultar la impunidad. Además, mostramos que éste es el uso dominante de la justicia transicional en Colombia, hecho por el gobierno y los líderes paramilitares, pero también apoyado implícitamente por la mayoría de la sociedad civil. Sin embargo, igualmente sostuvimos que el discurso de la justicia transicional puede ser usado de formas democráticas, esto es, como un instrumento para luchar contra la impunidad y para aplicar efectivamente los derechos de las víctimas. Y mostramos que éste ha sido un uso marginal pero en todo caso muy importante de la justicia transicional, hecho por los movimientos de víctimas, las organizaciones de derechos humanos, la Corte Constitucional, la Corte Suprema de Justicia y la Corte Interamericana de Derechos Humanos. De otra parte, sostuvimos que, en algunas circunstancias, la justicia transicional puede funcionar no sólo como discurso, sino también como restricciones virtuosas que, en lugar de ser un obstáculo a la paz, pueden encauzar las dinámicas políticas de las negociaciones de paz y, como resultado, acercar 
los intereses y las expectativas de actores antagónicos. También mostramos que esta interpretación puede ser útil para explicar el abrupto giro del gobierno colombiano y los paramilitares hacia el discurso de la justicia transicional, y la consecuente existencia de un consenso sobre la fuerza imperativa de estándares jurídicos con un mínimo núcleo duro, aceptado tanto por éstos como por las víctimas y las organizaciones de derechos humanos.

Una pregunta surge necesariamente de las conclusiones anteriores: ¿debería usarse el discurso de la justicia transicional en un contexto como Colombia? Algunos académicos y líderes sociales demuestran mucho escepticismo e incluso temor frente a este lenguaje, pues piensan que siempre conducirá a un uso manipulador ${ }^{68}$. La escena política colombiana muestra que este temor encuentra fundamento, pues el uso manipulador de la justicia transicional como instrumento para ocultar y legitimar la impunidad es dominante. Además, hay razones adicionales para tener reticencia frente al uso de la justicia transicional en el país. De un lado, el uso de ese discurso puede producir distorsiones agravadas. En efecto, en ausencia de una transición siquiera fragmentaria, el uso de la justicia transicional puede ser percibido como una justificación de un régimen especial permanente y privilegiado para tratar indulgentemente las atrocidades cometidas por actores poderosos. Esta percepción podría derivarse con facilidad del hecho de que, mientras que los paramilitares desmovilizados que han cometido incontables atrocidades reciben un castigo benévolo, la criminalidad de pequeña escala está siendo sometida a todo el rigor de la ley penal. Ciertamente, este contraste puede acentuar los problemas de inequidad y el sentimiento de impunidad que por lo general caracterizan los procesos ordinarios de justicia transicional ${ }^{69}$.

De otro lado, el uso del lenguaje de la justicia transicional en el contexto colombiano puede contribuir a garantizar la repetición, en lugar de la no repetición, de las atrocidades. De hecho, incluso si los mecanismos de justicia transicional fuesen usados adecuadamente -es decir, de manera democrática y no manipuladora-, las estructuras de poder del paramilitarismo podrían no ser desarticuladas en todo caso. Esto es así porque, cuando se trata de actores pro sistémicos, para garantizar la no repetición no basta con garantizar la verdad, la justicia y la reparación; es necesario implementar mecanismos específicos para asegurar que las estructuras políticas y económicas serán efectivamente desmontadas ${ }^{70}$. En ausencia de tales mecanismos, la impunidad puede terminar siendo legitimada y los reclamos de las víctimas silenciados.

Finalmente, el uso del discurso de la justicia transicional en Colombia puede conducir a análisis precarios de la situación. En efecto, si no está teniendo lugar una transición, parece difícil hablar de la necesidad de un equilibrio entre paz y justicia. Por consiguiente, parece difícil justificar, con base en la paz, restricciones a la protección completa de las víctimas.

Las ideas anteriores constituyen fuertes argumentos para rechazar el uso de la justicia transicional en Colombia. No obstante, existen también buenos argumentos para defender el uso de dicho discurso en el país. De un lado, como lo hemos argumentado en este artículo, existe un uso

68 Ver, por ejemplo, Cepeda, Ob. Cit.

69 Para el sentimiento de impunidad, ver, por ejemplo, Hamber, B. 2003. “Dealing with the Past: Rights and Reasons: Challenges for Truth Recovery in South Africa and Northern Ireland", Fordham International Law Journal, No.26, pp.1074-94.

70 Algunos ejemplos de mecanismos de ese tipo son: las purgas o leyes de depuración aplicadas a aquellas instituciones en las cuales la colusión con los paramilitares ha sido generalizada, como la fuerza pública; la investigación activa de todos los servidores públicos que han incurrido en colusión; la reforma de leyes e instituciones que permitieron la creación del paramilitarismo y sus estructuras de poder, tal como las leyes que admitían la delegación del uso de las armas a civiles -que son vistas como el origen de algunas formas de paramilitarismo-, la legislación electoral -cuyos débiles controles han permitido que las elecciones sean manipuladas por los actores armados-, o las leyes civiles que privilegian la propiedad formal sobre la propiedad real y sobre la posesión -que han permitido a los actores armados llevar a cabo una contrarreforma agraria-, entre muchas otras. 
democrático de la justicia transicional, que puede tener, y de hecho ha tenido, efectos políticos y jurídicos muy relevantes en el contexto colombiano. Tal uso de la justicia transicional ha puesto los derechos de las víctimas en el centro de cualquier discusión sobre cómo enfrentar la comisión de atrocidades. Como resultado, dicho uso de la justicia transicional ha generado el reconocimiento de las víctimas como sujetos políticos cuyos puntos de vista son importantes y, así, ha contribuido al empoderamiento de éstas. Más aún, el uso democrático de la justicia transicional ha producido la admisión de la idea de que la búsqueda de la paz no puede anular o arrasar con los derechos de las víctimas, así como el efecto práctico de ciertos ajustes al marco jurídico, tendientes a evitar una afectación desproporcionada de esos derechos. Adicionalmente, el uso democrático de la justicia transicional ha generado la producción de propuestas comunitarias o desde abajo sobre cómo proteger los derechos de las víctimas, que son muy valiosas.

De otro lado, como también lo mostramos en este artículo, los estándares jurídicos de la justicia transicional pueden operar como restricciones virtuosas que encauzan los procesos de negociación y que, al hacerlo, moldean normativamente esos propósitos, acercando así intereses y expectativas opuestas. Sin duda, el funcionamiento de los estándares jurídicos sobre derechos de las víctimas como restricciones virtuosas favorece la consolidación democrática en el largo plazo.

Finalmente, a pesar de sus falencias, el uso del lenguaje de la justicia transicional parece inevitable en el contexto colombiano. De hecho, incluso una transición precaria como la producida por las negociaciones de paz con los paramilitares tiene en su centro el dilema de paz versus justicia. En la situación actual, es imposible ignorar o dejar de lado este dilema, que constituye el principio básico de la justicia transicional. Además, el uso del discurso de la justicia transicional asegura que los derechos de las víctimas estarán al centro de todas las discusiones relativas a las negociaciones de paz. Aunque esto no asegura que dichos derechos serán protegidos adecuadamente, ciertamente contribuye al empoderamiento de las víctimas, ya que garantiza que sus derechos no estarán ausentes de ni serán invisibilizados en esas discusiones. Más aún, el uso del discurso de la justicia transicional abre la posibilidad de aprender de las enseñanzas teóricas y prácticas asociadas a los enfoques de la justicia transicional.

El carácter inevitable y el potencial democrático de la justicia transicional constituyen razones muy poderosas para no rechazar el uso de este discurso en Colombia. Sin embargo, en nuestro concepto, en un contexto como el colombiano sólo debería promoverse un uso cauteloso y no ingenuo de la justicia transicional. Esto significa, en primer lugar, que es sumamente importante tener conciencia de que hay usos y abusos de las ideas y propuestas de la justicia y transicional, e identificarlos con el fin de potencializar sus virtudes democráticas y de minimizar sus riesgos manipuladores. Dado que estos últimos parecen dominar la discusión política en Colombia, resulta crucial estar al tanto de la posible manipulación de la justicia transicional y criticarla siempre que la misma sea identificada. También resulta vital promover e incentivar el uso democrático de la justicia transicional, así como defenderlo en contra de ataques. Este uso de la justicia transicional tiene efectos democráticos muy importantes, y no necesariamente constituye un obstáculo a la paz, sino que incluso puede contribuir a ella a través de la imposición de restricciones virtuosas a las negociaciones políticas. Sin embargo, es importante tener en cuenta que, aunque muy importantes, los efectos de este uso de la justicia transicional son en todo caso limitados, pues se enfrentan a un uso manipulador de dicho discurso que domina la escena política.

En segundo lugar, un uso cauteloso y no ingenuo de la justicia transicional implica defender la existencia de un contenido mínimo pero no negociable de estándares jurídicos sobre derechos de las víctimas como restricciones virtuosas que no imponen obstáculos a las negociaciones de paz, sino que más bien las canalizan. En efecto, la idea de ese núcleo duro de estándares jurídicos puede ser percibida como una amenaza creíble por los actores de las negociaciones de paz, 
quienes, como resultado, pueden moverse hacia posturas menos radicales y hacia espacios más consensuales, en los cuales todos los actores admiten la imposibilidad de anular los derechos de las víctimas en favor de la paz y la necesidad de satisfacer estos derechos en algún grado.

En tercer lugar, un uso cauteloso y no ingenuo de la justicia transicional en Colombia implica evitar una potencial deficiencia derivada de la aplicación estándar de ese enfoque a negociaciones de paz con actores pro sistémicos o cercanos al Estado. Como lo mencionamos en este artículo, las diferencias entre estos actores y los actores antisistémicos o enemigos del Estado (como los grupos guerrilleros) son relevantes. Así, por ejemplo, cuando entregan sus armas, los actores antisistémicos entregan casi todo su poder; en contraste, una organización paramilitar puede entregar sus armas y, no obstante, retener la mayoría de su poder, entre otras razones porque su poder está relacionado con los vínculos que ostenta con las autoridades estatales. Por lo tanto, en procesos de negociación con actores pro sistémicos, es importante aplicar medidas específicas y más drásticas de no repetición que aquéllas usualmente aplicadas a las fórmulas de justicia transicional.

Más aún, las diferencias entre actores pro sistémicos y antisistémicos son relevantes para identificar la manera en la cual el régimen político oficial permitió la comisión de atrocidades y, por ende, para proponer reformas institucionales dirigidas a impedir dichas atrocidades en el futuro. En efecto, como lo ha anotado Michael Fehrer, la estigmatización del régimen anterior es fundamental en una transición para garantizar la no repetición de las atrocidades. A través de ella, es posible asignar responsabilidad no sólo a actores individuales, sino también a proyectos políticos ${ }^{71}$. En el caso del paramilitarismo en Colombia, esto implicaría exponer y estigmatizar los diferentes niveles de omisión y colusión de los agentes del Estado con los paramilitares, que implicaron la ausencia de una efectiva persecución de los últimos y la corrupción de los primeros, y que por consiguiente permitieron la comisión de atrocidades. La estigmatización de estos vínculos entre los grupos paramilitares y el Estado debería traer como resultado propuestas específicas de reforma, encaminadas a dar un fin absoluto a dichos vínculos y a impedir su repetición en el futuro.

En último lugar pero no por ello menos importante, un uso cauteloso y no ingenuo de la justicia transicional en un contexto en el cual no está teniendo lugar una transición exige una reconsideración sistemática del marco conceptual y de las recomendaciones usuales de la justicia transicional, con el fin de comprender cómo deberían aplicarse a conflictos aún en curso, o a negociaciones parciales con algunos de los actores armados de un conflicto. Un buen ejemplo de esto es el siguiente: las Comisiones de la Verdad constituyen un instrumento habitualmente recomendado para promover la protección del derecho a la verdad en las transiciones de la guerra a la paz; sin embargo, no es de ninguna manera claro que una Comisión de la Verdad podría operar adecuadamente en un conflicto armado aún en curso como el colombiano, en razón de los agudos problemas de seguridad de las víctimas y de la posibilidad de producir versiones fragmentarias o incompletas de la verdad, entre otros problemas.

La reconsideración de la forma en la que operan el marco conceptual y las recomendaciones usuales de la justicia transicional en medio de un conflicto armado también es importante para evitar usos

\footnotetext{
71 De acuerdo con Fehrer, sin una estigmatización del régimen anterior, las atrocidades cometidas en países en los cuales el Estado no se ha consolidado aún plenamente pueden explicarse como resultado de conflictos propios de regímenes predemocráticos, y no como el resultado de regímenes no democráticos o autoritarios. Estas explicaciones son problemáticas, pues excluyen a las "democracias nacientes" -como Colombia y muchos otros países del sur global- de la exigencia de aplicar el Estado de derecho a los victimarios de atrocidades. En efecto, las atrocidades son interpretadas como el producto de una etapa de conflicto entre facciones, previo a la consolidación del Estado y del Estado de derecho. Por ende, la reconciliación puede ser vista como un proceso de civilización, como un salto cultural de la barbarie a la consolidación de un régimen democrático. Ver Fehrer, M. 1999. Terms of Reconciliation", in Hesse, C. \& Post, R. (eds.). Human Rights in Political Transitions. Gettysburg to Bosnia. New York: Zone Books.
} 
manipuladores de la justicia transicional. Por ejemplo, aunque la reconciliación es, sin duda, un concepto clave en el discurso de la justicia transicional, ésta debe interpretarse en función de las particularidades del contexto colombiano. De hecho, mientras que en algunos contextos -como aquél de la transición sudafricana- la noción de reconciliación puede haber sido definida en un sentido grueso o maximalista, que implica cercanía entre víctimas y victimarios, ésta no parece ser una buena idea para Colombia ${ }^{72}$. Dadas las relaciones asimétricas de poder entre víctimas y victimarios, y dado el rechazo de la idea de perdón por parte de muchas víctimas, una noción democrática de reconciliación parece mucho más apropiada para el contexto colombiano.

\section{Bibliografía}

Libros, artículos, conferencias e informes

Botero, C. y Restrepo, E. 2006. "Estándares internacionales y procesos de transición en Colombia", en Uprimny, R., Botero, C., Restrepo, E. y Saffon, MP. 2006. ¿Justicia transicional sin transición? Verdad, justicia y reparación para Colombia. Bogotá: DeJuSticia.

Bourdieu, P. 2000. La fuerza del derecho. Bogotá: Uniandes.

2001. "Las formas de capital", en: Poder, derecho y clases sociales, Bilbao: Desclée de Brower, Capítulo IV.

Cepeda, I. 2007. Conferencia para el panel "Fundamentos éticos y políticos para la reconstrucción del país", presentada en el seminario Reconstrucción de Colombia, organizada por Planeta Paz, DeJuSticia, CODHES, Fundación Manuel Cepeda Vargas y Unijus. Bogotá, agosto de 2007.

CNRR. 2006. Fundamentos Filosóficos y Operativos. Definiciones estratégicas de la Comisión Nacional de Reparación y Reconciliación, disponible en: www.cnrr.org.co/cd/pdf/Definiciones_ estratergicas.pdf.

Hoja de Ruta, disponible en: www.cnrr.org.co/hoja_de_ruta.htm.

Crocker, D. 2002. "Democracy and Punishment: Punishment, Reconciliation, and Democratic Deliberation," Buffalo Criminal Law Review, No.5, pp. 509-49.

Díaz, C. 2007. "Challenging Impunity from Below: The Contested Ownership of Transitional Justice in Colombia", próxima publicación.

Elster, J. 2004. Closing the Books. Transitional Justice in Historical Perspective. Cambridge: Cambridge University Press.

García Villegas, M. 1994. La eficacia simbólica del derecho. Bogotá: Ediciones Uniandes.

Gómez-Müller, A. 2007. "Olvido, ideología y memoria", Conferencia presentada en el seminario Reconstrucción de Colombia, organizado por Planeta Paz, DeJuSticia, CODHES, Fundación Manuel Cepeda Vargas y Unijus. Bogotá, agosto de 2007.

González, C. "Prólogo". 2007, en Las cifras del conflicto. Bogotá: INDEPAZ.

Hamber, B. 2003. "Dealing with the Past: Rights and Reasons: Challenges for Truth Recovery in South Africa and Northern Ireland", Fordham International Law Journal, No.26, pp.1074-94.

IEPRI (ed.). 2006. Nuestra guerra sin nombre. Transformaciones del conflicto en Colombia. Bogotá: Norma.

\footnotetext{
72 Muchos tampoco la consideraron una buena idea en el contexto sudafricano. Ver Crocker, Ob. Cit.; Hamber, Ob. Cit.
} 
Joinet, L. (1997). ONU, Comisión de Derechos Humanos, 49vo periodo de sesiones. Informe final revisado acerca de la cuestión de la impunidad de los autores de violaciones de los derechos humanos (derechos civiles y políticos) preparado por el Sr. L. Joinet de conformidad con la resolución 1996/119 de la Subcomisión. Doc. E/CN.4/Sub.2/1997/20/Rev. 1.

Kennedy, D. 1999. Libertad y restricción en la decisión judicial. El debate con la Teoría Crítica del Derecho (CLS). Bogotá: Siglo del Hombre Editores (Diego Eduardo López ed.).

López, A. 2006. "Narcotráfico, ilegalidad y conflicto en Colombia", en IEPRI (ed.), 2006. Nuestra guerra sin nombre. Transformaciones del conflicto en Colombia. Bogotá: Norma.

Múnera, L. 2006. "Proceso de paz con actores armados ilegales y parasistémicos (los paramilitares y las políticas de reconciliación en Colombia)", Revista Pensamiento Jurídico No 17.

Nalepa, M. 2003. "Suffer a Scratch to Avoid a Blow? When Post-Communists Hurt Themselves: A Model of Transitional Justice Legislation", en el momento manuscrito no publicado, Departamento de Ciencia Política, Universidad de Columbia University, citado en: Elster, J. 2004. Closing the Books. Transitional Justice in Historical Perspective. Cambridge: Cambridge University Press.

Orentlicher, D. (2004). ONU, Comisión de Derechos Humanos, 60vo periodo de sesiones. Estudio independiente, con inclusión de recomendaciones, sobre las mejores prácticas para ayudar a los Estados a reforzar su capacidad nacional con miras a combatir todos los aspectos de la impunidad. Doc. E/CN.4/ 2004/88.

Pizarro, E. 2006. Conferencia con ocasión del Coloquio Internacional Reparaciones a las víctimas en Colombia y Perú: Retos y perspectivas. Bogotá: Alianza Francesa, diciembre de 2006, disponible en: www.pucp.edu.pe/idehpucp//imagesdocs/ponencia\%20de\%20eduardo\%20 pizarro.doc.

Rajagopal, B. 2003. International Law from Below. Development, Social Movements and Third World Resistance. Cambridge: Cambridge University Press.

Richards, M. 2007. Quantification of the financial resources required to repair victims of the Colombian conflict in accordance with the Justice and Peace Law. Bogotá: CERAC.

Romero, M. 2003. Paramilitares y autodefensas. 1982-2003. Bogotá: IEPRI-Planeta.

Saffon, MP. 2006. Poder paramilitar y debilidad institucional. El paramilitarismo en Colombia: un caso complejo de incumplimiento de normas. Bogotá: Universidad de los Andes, tesis de maestría.

Saffon, MP y Uprimny, R. 2007. "Las masacres de Ituango contra Colombia: Una sentencia de desarrollo incremental", Revista CEJIL: Debates sobre Derechos Humanos y el Sistema Interamericano $\mathrm{N}^{\circ} 3$.

Sánchez, G. and Peñaranda, R. 1991. Pasado y presente de la violencia en Colombia. Bogotá: IEPRI-CEREC.

Santos de Sousa, B. 1998. La globalización del derecho. Bogotá: Universidad Nacional de Colombia \& ILSA.

Santos de Sousa, B. y Rodríguez, C. (eds.). 2005. Law and Globalization from Below: Towards a Cosmopolitan Legality. Cambridge: Cambridge University Press.

Uprimny, R. 2006. "Entre el protagonismo, la precariedad y las amenazas: las paradojas de la judicatura", en Leal, F. (ed.), En la encrucijada, Colombia siglo XXI. Bogotá: Norma.

Uprimny, R., Botero, C., Restrepo, E. y Saffon, MP. 2006. ¿Justicia transicional sin transición? Verdad, justicia y reparación para Colombia. Bogotá: DejuSticia. 
Uprimny, R. y Saffon, MP. 2006. "La ley de 'justicia y paz': ¿una garantía de justicia y paz y de no repetición de las atrocidades?", en Uprimny, R., Botero, C., Restrepo, E. y Saffon, MP, Ob. Cit.

Uprimny, R. y Saffon, MP. 2007. "Plan Nacional de Desarrollo y reparaciones. Propuesta de un programa nacional masivo de reparaciones administrativas para las víctimas de crímenes atroces en el marco del conflicto armado". Bogotá: CODHES. En prensa.

Uprimny, R. y Saffon, MP. 2007. "Transitional Justice, Restorative Justice and Reconciliation. Some Insights from the Colombian Case", disponible en: www.global.wisc.edu/reconciliation/.

Páginas web

Acción Social, Estadísticas de la población desplazada, disponible en: www.accionsocial.gov.co/ contenido/contenido.aspx?cat ID=383\&conID=556.

ACNUR, 2006. Global Trends Refugees, Asylum-seekers, Returnees, Internally Displaced and Stateless Persons, junio de 2007, disponible en: www.unhcr.org/ statistics.html.

Artículos de prensa

"Juicio histórico a paramilitares", El Tiempo, abril 23 de 2007.

"La gran encuesta de la parapolítica", Revista Semana, mayo 5 de 2007.

"Para-políticos" y "El ventilador de Mancuso", Revista Semana, mayo 19 de 2007.

"Vinieron, hablaron y se fueron. Armando Neira relata en exclusiva para SEMANA.COM los detalles de la polémica visita de los paramilitares al Congreso", Semana.com, julio 29 de 2005.

Constitución, leyes, decretos y proyectos de ley

Constitución Política de Colombia, 1991.

Decreto No 3391 de 2006, Colombia.

Decreto $N^{\circ} 4436$ de 2006, Colombia.

Ley 782 de 2002, Colombia.

Ley 975 de 2005 (Ley de Justicia y Paz), Colombia.

Proyecto de Ley de Alternatividad Penal, Gaceta del Congreso № 436 de 2003.

Proyecto de Ley "Por la cual se dictan disposiciones para garantizar los derechos a la verdad, la justicia y la reparación de las víctimas de violaciones a los derechos humanos y de la sociedad colombiana en procesos de reconciliación con grupos armados al margen de la ley".

Proyecto de Ley "Por la cual se dictan normas sobre Verdad, Justicia, Reparación, Prevención, Publicidad y Memoria para el sometimiento de los grupos paramilitares que adelanten diálogos con el gobierno".

Sentencias

Corte Constitucional de Colombia, sentencia C-127 de 2006. sentencia C-319 de 2006. sentencia C-370 de 2006. sentencia C-455 de 2006. sentencia C-531 de 2006. sentencia C-575 de 2006. sentencia C-650 de 2006. 
, sentencia C-670 de 2006.

sentencia C-719 de 2006.

sentencia C-080 de 2007.

Corte Interamericana de Derechos Humanos, Caso Barrios Altos, sentencia de marzo 14 de 2001, serie C N 75 .

Caso de la masacre de 19 comerciantes vs. Colombia, sentencia de julio 5 de 2004, serie C No 109.

Caso de la masacre de Mapiripán vs. Colombia, sentencia de septiembre 15 de 2005, serie $C \mathrm{~N}^{\mathrm{o}} 134$.

, Caso de la masacre de Pueblo Bello vs. Colombia, sentencia de enero 31 de 2006, serie C N 140 .

Caso de las masacres de Ituango vs. Colombia, sentencia de julio 1 de 2006, serie C $\mathrm{N}^{\circ} 149$.

Caso de la masacre de La Rochela vs. Colombia, sentencia de mayo 11 de 2007, serie $\mathrm{CN}^{\circ} 163$. 